\title{
EL CONFLICTO ENTRE EL DERECHO AL OLVIDO Y LA LIBERTAD DE INFORMACIÓN DE LA PRENSA CONTENIDA EN HEMEROTECAS
}

\section{The conflict between the right to be forgotten and the freedom of expression in news contained in digital press archives}

\author{
NURIA MARTÍNEZ MARTÍNEZ \\ Universidad de Alicante \\ n.martinez@ua.es
}

Cómo citar/Citation

Martínez Martínez, N. (2019).

El conflicto entre el derecho al olvido y la libertad de información de la prensa contenida en hemerotecas.

Derecho Privado y Constitución, 34, 51-95.

doi: https://doi.org/10.18042/cepc/dpc.34.02

(Recepción: 27/01/2019; aceptación tras revisión: 10/06/2019; publicación: 26/06/2019)

\section{Resumen}

A raíz de las sentencias del Tribunal Constitucional de 4 de junio y del Tribunal Europeo de Derechos Humanos de 28 de junio, ambas de 2018, el presente trabajo tiene por objeto analizar el conflicto entre el derecho al olvido y la libertad de información en relación con un supuesto concreto: el uso del nombre y apellidos en noticias contenidas en hemerotecas digitales. Para ello, se analiza en primer lugar si los archivos digitales de la prensa quedan amparados por la libertad de información y, en segundo, se estudian los criterios de ponderación necesarios para equilibrar los derechos en liza, en especial, la relevancia pública de la información tras el paso del tiempo. Finalmente, se determinan las medidas adecuadas para el restablecimiento 
del derecho al olvido y se comparan con las aportadas por las recientes normas que lo han reconocido legalmente, en concreto, con el RGPD y la LOPDGDD.

\section{Palabras clave}

Derecho al olvido; libertad de información; hemerotecas digitales; ponderación de derechos.

\section{Abstract}

As a result of the judgements of the Spanish Constitutional Court of $4^{\text {th }}$ June and the European Court of Human Rights of $28^{\text {th }}$ June, both of 2018, the purpose of this paper is to analyse the conflict between the right to be forgotten and freedom of information in relation to a specific situation: the use of the name and surnames in news contained in digital press archives. Firstly, it is considered if the digital archives of the press are protected by the freedom of information and, secondly, the weighting criteria to balance the rights at issue are studied, especially, the public relevance of the information after the passage of time. Finally, the appropriate measures for the restoration of the right to be forgotten are determined and compared with those provided by the recent legal instruments that have recognized it, in particular, with the GDPR and the LOPDGDD.

\section{Keywords}

Right to be forgotten; freedom of information; digital press libraries; weighting of rights. 


\section{SUMARIO}

I. INTRODUCCIÓN. II. LA CONFRONTACIÓN ENTRE EL DERECHO AL OLVIDO Y LA LIBERTAD DE INFORMACIÓN ANTE EL TC Y EL TEDH: 1. La STC de 4 de junio de 2018. 2. La STEDH de 28 de junio de 2018 (caso M. L. y W. W. c. Alemania). III. LAS HEMEROTECAS DIGITALES DE LA PRENSA Y SUS FUNCIONES. IV. LA FRONTERA ENTRE EL DERECHO AL OLVIDO Y LA LIBERTAD DE INFORMACIÓN. CRITERIOS PARA SU DELIMITACIÓN Y MEDIDAS DE RESTABLECIMIENTO DEL DERECHO AL OLVIDO: 1. La veracidad de la información. 2. La relevancia pública de la información. El tiempo como factor determinante para su valoración en el conflicto con el derecho al olvido. 3. Medidas para el restablecimiento del derecho al olvido. El grado de difusión de la información como criterio para su determinación. V. CONCLUSIONES Y COMPARATIVA CON EL ALCANCE DEL DERECHO AL OLVIDO FRENTE A LAS HEMEROTECAS SEGÚN SU RECIENTE RECONOCIMIENTO LEGAL. BIBLIOGRAFÍA.

\section{INTRODUCCIÓN}

En el conocido caso Google, el TJUE puso de relieve, entre otros muchos aspectos, que el tratamiento de datos personales que llevan a cabo los buscadores generales de internet no equivale en todo caso a aquel que desarrolla el titular de la página web que publica la información o webmaster, titular que, en el caso en cuestión, era un periódico en su versión digital ${ }^{1}$. En el supuesto en cuestión, el Tribunal concluyó que la Directiva 95/46/CE preveía, al menos de forma implícita, un derecho al olvido frente a los buscadores, entendiendo que ello era así "también en el supuesto de que este nombre o esta información no se borren previa o simultáneamente de estas páginas web, y, en su caso, aunque la publicación en dichas páginas sea en sí misma lícita ${ }^{2}$. Es decir, aunque el uso del nombre y apellidos como criterios de búsqueda en un buscador general sea considerado vulnerador del derecho al olvido en ciertos casos, el tratamiento de tales datos por parte del webmaster puede ser acorde con la normativa protectora de datos personales como, por ejemplo,

STJUE, de 13 de mayo de 2014, asunto C-131/12, TJCE/2014/85, párrs. 86-88.

2 Párr. 88. 
cuando su uso se lleve a cabo en el legítimo ejercicio del derecho a la libertad de información.

Resuelto el asunto sobre el conflicto «olvido/buscador», resulta necesario hacer lo mismo en relación con la controversia «olvido/webmaster». Así, ¿sería posible ejercitar el mismo derecho frente a la prensa digital por los contenidos de su hemeroteca y cuál sería su alcance? Pues bien, recientemente el TC, en su sentencia de 4 de junio de $2018^{3}$, y el TEDH, en la de 28 de junio de $2018^{4}$, han tenido ocasión de pronunciarse sobre esta polémica cuestión. Se trata, en definitiva, de resolver el conflicto existente entre el derecho al olvido, como mecanismo para limitar el potencial ofensivo de la informática en relación con el honor, la intimidad y la dignidad de la persona, y la libertad de información de los editores de prensa en relación con las noticias contenidas en sus hemerotecas digitales. De ello nos ocuparemos en las siguientes páginas, si bien conviene hacer ciertas precisiones previas.

En primer lugar, debe tenerse en cuenta que la norma aplicable al caso resuelto por el TC en su sentencia de 4 de junio de 2018 era la Ley Orgánica 15/1999, de 13 de diciembre, de Protección de Datos de Carácter Personal (LOPD). En la misma, no se reconocía de forma explícita el denominado derecho al olvido, de modo que la interpretación llevada a cabo por el Tribunal se realiza con base en los principios configuradores de la protección de datos y en la jurisprudencia previa que había creado este derecho. Por tanto, en este trabajo se analiza el contenido que, según el TC y el TEDH, debería abarcar el derecho al olvido cuando se enfrenta con la libertad de información por las noticias contenidas en hemerotecas digitales y no cómo ha sido finalmente regulado. No obstante, y tras precisar cómo debería resolverse el conflicto en cuestión a nuestro parecer, se realizará una breve comparativa con la normativa vigente 5

Y, en segundo lugar, es cierto que el Reglamento General de Protección de Datos (RGPD) ${ }^{6}$ emplea en el título de su art. 17 el término «derecho de supresión ("derecho al olvido")», por lo que podría considerarse más apropiada dicha denominación. No obstante, en este trabajo hemos preferido la segunda expresión por varias razones. Por un lado, porque es el nombre con

STC 58/2018, de 4 de junio de 2018, RTC/2018/58.

4 STEDH, de 28 de junio de 2018, TEDH/2018/67, en adelante, caso M. L. y W. W. c. Alemania.

5 Vid. infra, apartado V.

6 Reglamento (UE) 2016/679 del Parlamento Europeo y del Consejo, de 27 de abril de 2016, relativo a la protección de las personas físicas en lo que respecta al tratamiento de datos personales y a la libre circulación de estos datos y por el que se deroga la Directiva 95/46/CE. 
el que tradicionalmente se ha designado a este derecho. Por otro, porque el propio RGPD se refiere al mismo en distintos considerandos como "derecho al olvido ${ }^{7}$, así como en el título del art. 17, aunque de forma entrecomillada. Igualmente, la vigente Ley Orgánica 3/2018, de 5 de diciembre, de Protección de Datos Personales y garantía de los derechos digitales (LOPDGDD) reconoce el «derecho al olvido» en sus arts. 93 y $94^{8}$. Y, por último, porque tanto el TC como el TEDH han empleado la expresión "derecho al olvido» en las sentencias de las que trae causa esta investigación.

Hechas estas consideraciones, pasemos a analizar los casos que justifican el presente artículo.

\section{LA CONFRONTACIÓN ENTRE EL DERECHO AL OLVIDO Y LA LIBERTAD DE INFORMACIÓN ANTE EL TC Y EL TEDH}

\section{LA STC DE 4 DE JUNIO DE 2018}

En 1985, el periódico El País publicó en su versión en papel una noticia relativa a la detención de siete personas por su pertenencia a una red de tráfico de estupefacientes en la que estaba involucrado el hermano de un político relevante. Entre los implicados, la noticia mencionaba a dos hermanas, identificadas con su nombre, apellidos y profesión, que, además de su participación en los hechos, sufrían un fuerte síndrome de abstinencia como consecuencia de su drogadicción.

En el año 2007, El País puso a disposición del público su hemeroteca digital de forma gratuita. Cabe destacar que el periódico incentivó que los buscadores generales de internet encontraran la noticia en cuestión a través del nombre y los apellidos de las dos hermanas, mediante la inclusión de los comandos index y follow. Consecuencia de ello, al introducir tales datos como criterios de búsqueda, dicha información aparecía entre los primeros resultados de Google y Yahoo.

En 2009, las dos hermanas solicitaron a El Pais y a Google el cese en el tratamiento de sus datos personales. Ante la negativa del buscador y la falta de contestación del periódico, las titulares de los datos formularon reclamación ante la AEPD por vulneración del derecho de oposición previsto en el art. 18 LOPD. Aunque la Agencia no la estimó en relación con Google por cuestiones

\footnotetext{
Véanse considerandos 65, 66 y 156.

8 Dicha ley deroga la anterior LOPD y está en vigor, de acuerdo con su disposición final decimosexta, desde el día 7 de diciembre de 2018.
} 
de forma, atendió la reclamación frente a El Pais por no haberse acreditado contestación alguna a las hermanas, instando al periódico a que en el plazo de diez días procediera a la cancelación de los datos o justificara las razones por las que no procedía tal actuación`. Conviene poner de relieve que en estas resoluciones la AEPD indicó a El País la posibilidad de aplicar medidas técnicas que, sin alterar su archivo histórico, limitaran la indexación de los nombres y apellidos por parte de los buscadores generales ${ }^{10}$.

Finalmente, las hermanas decidieron interponer demanda frente al periódico El Pais por vulneración de los derechos al honor, a la intimidad y a la protección de datos personales en vía civil ${ }^{11}$. El País, por su parte, alegó que su conducta estaba amparada por el derecho a la libertad de información.

9 Resoluciones n. ${ }^{\circ}$ R/00085/2010 y n. ${ }^{\circ}$ R/00094/2010. A ellas se refieren Rallo (2014: 115-119) y Di Pizzo Chiacchio (2018: 101-102).

10 En concreto, en el FD 8 de ambas resoluciones, se planteaba «la conveniencia de que, en el caso de que concurra un interés legítimo de un particular y manteniendo la información inalterable en su soporte, dado que no se borraría de sus archivos ni de sus históricos, desde la webmaster se evite la indexación de la noticia por los motores de búsqueda en Internet, lo que limitaría su divulgación indiscriminada, permanente y, en su caso, lesiva. Por ello, se traslada a ese Diario la posibilidad de que se realicen las actuaciones oportunas para limitar la indexación del nombre y apellidos de Doña A.A.A. en el documento mencionado anteriormente, con objeto de que en el futuro los motores de búsqueda de internet no puedan asociarlo a la interesada». Esta recomendación sería reiterada posteriormente, entre otras, en las resoluciones n. ${ }^{\circ} \mathrm{R} / 00898 / 2010$, n. ${ }^{\circ} \mathrm{R} / 02319 / 2010$, n. ${ }^{\circ} \mathrm{R} / 00089 / 2014$ y n. ${ }^{\circ} \mathrm{R} / 00388 / 2014$.

11 En cuanto a ello, Di Pizzo Chiacchio (2018: 181) llama la atención sobre el hecho de que las hermanas no siguieran el procedimiento tuitivo preferente en cuanto a la protección de sus datos personales, esto es, tras acudir ante la vía administrativa por medio de reclamación ante la AEPD, lo que sí llevaron a cabo, es posible el recurso frente a su resolución ante la jurisdicción contencioso-administrativa, resolviéndose por la AN y, posteriormente por la Sala Tercera del TS, en su caso. No obstante, las demandantes no acudieron a la jurisdicción contencioso-administrativa, sino ante la civil, probablemente, como señala el mismo autor, por la posibilidad que le ofrece esta última de solicitar una indemnización por daños y perjuicios junto con la declaración de vulneración del derecho a la protección de datos. A esta circunstancia, cabe añadir y tener en cuenta que las actoras del supuesto comentado también ejercitaron la acción declarativa de vulneración de sus derechos al honor y a la intimidad, lo que únicamente puede llevarse a cabo ante la jurisdicción civil. En este sentido, la SAN, de 24 de febrero de 2011, JUR/2011/94901, recuerda la importancia de desvincular la protección de datos de la vulneración del derecho al honor, respecto al cual el art. 1 LO 1/1982, de 5 de mayo, sobre protección civil del derecho al honor, a la intimidad personal y familiar y a la propia imagen $(\mathrm{LOPH})$ establece que «será protegido 
El Juzgado de Primera Instancia de Barcelona falló a favor de las hermanas por considerar que la noticia carecía de veracidad cuando se publicó en la hemeroteca transcurridos más de veinte años desde el acontecimiento de los hechos que la justificaron, pues sus antecedentes penales ya habían sido cancelados, además de que las actoras no tenían relevancia pública ${ }^{12}$. Concluyó el juzgador que la puesta a disposición de la noticia por medio de la hemeroteca únicamente tenía un propósito mercantilista y no cumplía una finalidad periodística, razón por la que consideró vulnerados los derechos al honor, a la intimidad y a la protección de los datos personales de las demandantes. En consecuencia, condenó a El País al cese inmediato en relación con la difusión de la información, imponiéndole la obligación de introducir el comando no index en su código fuente para impedir que la noticia apareciera como resultado en los buscadores como Google, así como al pago de una indemnización de 7000 euros a cada una de las actoras.

Frente a dicha resolución, fue interpuesto recurso de apelación por $E l$ País. Por su parte, las actoras impugnaron la sentencia por incongruencia omisiva, ya que en el petitum de la demanda también habían solicitado que se suprimieran su nombre y apellidos de la noticia o, subsidiariamente, que fueran sustituidos por sus iniciales y nada había contestado al respecto el juzgador de instancia. La AP de Barcelona compartió los argumentos de la sentencia recurrida, pero la revocó parcialmente al exigir no solo la desindexación, sino también el cese en el tratamiento de los datos personales en la página del webmaster, impidiendo el uso del nombre y apellidos de las titulares de los mismos, así como de sus iniciales en la noticia ${ }^{13}$.

El País volvió a sostener que su conducta estaba amparada por el art. 20.1 d) CE mediante la interposición de un recurso de casación ante el TS, que resolvió la cuestión en sentencia de 15 de octubre de $2015^{14}$. El TS consideró que la noticia seguía siendo veraz, a diferencia de la solución aportada en instancia y apelación, pero el paso del tiempo había hecho que el tratamiento de

civilmente» (FJ 3) y, por ello, «[...] la Agencia Española de Protección de Datos no es el órgano competente para dirimir controversias en materia de honor, intimidad personal y propia imagen por parte de los medios de comunicación [...]» (FJ 1). De hecho, la propia AEPD remite a la vía civil y a la LOPH en los supuestos en los que los solicitantes de protección de sus datos personales alegan infracción de los derechos al honor y a la intimidad frente a un medio de comunicación, como en sus recientes resoluciones n. ${ }^{\circ} \mathrm{R} / 00320 / 2018$ y n. ${ }^{\circ} \mathrm{R} / 00136 / 2018$, entre otras.

12 Sentencia del Juzgado de Primera Instancia de Barcelona, 156/2012, de 4 octubre, AC/2014/856.

13 SAP Barcelona 486/2013, de 11 octubre, AC/2013/1921.

14 STS, Sala Primera, 545/2015 de 15 octubre, RJ/2015/4417. 
los datos vulnerara el derecho al olvido digital, construido sobre el principio de calidad establecido en el art. 4.1 LOPD, es decir, el tratamiento de los datos había devenido inadecuado, no pertinente y excesivo en relación con la finalidad periodística para la que fueron recogidos. Por ello, el TS entendió infringido el derecho de protección de datos personales de las hermanas, vulneración que trajo consigo la intromisión ilegítima en sus derechos al honor y a la intimidad. No obstante, el Tribunal afirmó que las hemerotecas digitales cumplen un papel fundamental en la conservación de la información, por lo que las considera como «un bien jurídico protegido por la libertad de expresión (en el sentido amplio del art. 10 del Convenio de Roma, que engloba la libertad de información), que excluye las medidas que alteren su contenido eliminando o borrando datos contenidos en ellos, como puede ser la eliminación de los nombres de las personas que aparecen en tales informaciones o su sustitución por las iniciales» (FD 7). Por ello, el TS estimó que la medida adecuada para restablecer a las recurrentes en sus derechos al tiempo que se protege la libertad de información de la prensa era únicamente la de desindexar la noticia de los buscadores generales, manteniendo la posibilidad de indexarla en el buscador interno de la hemeroteca digital y conservando inalterada la noticia en la página web, esto es, con el nombre y los apellidos.

Aunque El País estuvo de acuerdo con la solución aportada por el TS, las hermanas consideraron que tal resolución establecía unas medidas que seguían vulnerando sus derechos al honor, a la intimidad y a la protección de datos, razón por la que interpusieron recurso de amparo ante el TC, resuelto por sentencia de 4 de junio de 2018. La razón que justificó la admisión del recurso fue que el TC todavía no había tenido ocasión de pronunciarse sobre «el "derecho al olvido" o "derecho al olvido digital" como posible proyección del derecho al honor, a la intimidad o a la protección de datos de carácter personal, en relación con las hemerotecas digitales y su eventual consideración como uno de los ámbitos a través de los cuales se puede manifestar el ejercicio de las libertades informativas» (FJ 4). Además, el elemento que diferenciaba este supuesto de anteriores conflictos relacionados con el derecho al olvido era que el mismo se alegaba frente al tratamiento de datos que realiza la página web que publica la noticia y no frente al buscador (FJ 6).

Al igual que el TS, el TC declaró que la noticia era veraz. En cambio, el criterio que jugó en contra de la prevalencia de la libertad de información en el caso concreto fue la relevancia pública de tal información, que había desaparecido por el transcurso del tiempo. Además de que las hermanas no eran personajes públicos, en el asunto resuelto la noticia no tuvo un especial impacto en la sociedad por tratarse de un delito menos grave de contrabando (FJ 8). Por su parte, la universalización de la información a través de internet multiplica el riesgo de injerencia en los derechos de la personalidad, razón por 
la que el TC consideró que se había causado un daño desproporcionado a las recurrentes en sus derechos al honor, la intimidad y protección de datos personales, por el descrédito que provocaba la nueva difusión de la noticia (FJ 8). En este contexto, el TC coincidió con el TS en que la desindexación de la noticia respecto a los buscadores generales era una medida idónea, necesaria y proporcionada para restablecer a las hermanas en sus derechos. Si bien, entendió que la información también debía ser desindexada del buscador interno de la hemeroteca digital de El País, pudiendo localizarse por cualquier otro criterio distinto al de los datos identificativos de las recurrentes. No obstante, los nombres y apellidos se habían de conservar en la noticia, pues su supresión, en opinión del Tribunal, supondría una injerencia innecesaria en la libertad de información, ya que la difusión de la noticia se habría visto suficientemente limitada u oscurecida con la desindexación de los buscadores generales y el interno de la hemeroteca $(\mathrm{FJ} 8)^{15}$.

\section{LA STEDH DE 28 DE JUNIO DE 2018 (CASO M. L. Y W. W. C. ALEMANIA)}

El litigio trae causa del asesinato de un afamado actor por parte de dos hermanastros alemanes en el año 1991, hecho por el que fueron condenados a cadena perpetua en 1993, si bien únicamente sobre pruebas indiciarias. Por ello, los condenados interpusieron diversos recursos de revisión y acudieron en varias ocasiones a la prensa para defender su versión de los hechos e informar sobre el procedimiento en cuestión. No obstante, todos los recursos fueron desestimados, el último de ellos en el año 2000 por el Tribunal Constitucional alemán.

Haciéndose eco de dicha resolución, la emisora de radio Deutschlandradio publicó un reportaje sobre los hechos y lo archivó en su página web en el apartado de «informaciones menos recientes» hasta 2007. Por su parte, la revista Der Spiegel mantenía en su archivo digital un fichero con el título «W. S. - un asesinato a martillazos» que incluía cinco artículos aparecidos entre 1991 y 1993 en los que se detallaban los hechos, la investigación y el procedimiento judicial, incluyendo los nombres y apellidos y fotos de los condenados en el juicio. No obstante, el acceso a dicho fichero estaba sometido al pago de una suscripción al contenido. De forma similar, el diario Mannheimer Morgen mantenía en el apartado «informaciones menos recientes» de su hemeroteca digital una noticia sobre los hechos publicada en el año 2001. Aunque el acceso al texto completo quedaba restringido a los suscriptores del diario, todos los internautas podían activar un enlace que resumía el contenido de la noticia, indicando el nombre y los apellidos de los condenados.

15 Cabe destacar que el Ministerio Fiscal también mantuvo la postura del TC. 
Ante tales hechos, estos interpusieron demandas contra los distintos medios de prensa en el año 2007 con el objeto de eliminar sus datos personales de los reportajes. La resolución de todas ellas tuvo el mismo resultado en las instancias judiciales alemanas inferiores. En la primera, el Tribunal Regional de Hamburgo consideró que el interés del público por la información debía ceder ante el de los demandantes en relación con no ser identificados con el acto, pues había transcurrido mucho tiempo desde su condena. A la misma conclusión llegó el Tribunal de Apelación de Hamburgo, para el que se había producido una vulneración del derecho a la intimidad de los condenados, los cuales debían ser especialmente protegidos para conseguir el objetivo de la rehabilitación en la sociedad. Asimismo, estimó que el borrado de los datos personales de los reportajes suponía una injerencia mínima en la libertad de información, pues la difusión de la misma no se prohibía y con tal medida no se falseaba la historia.

En cambio, el Tribunal Federal de Justicia anuló en 2009 las resoluciones previas por considerar que, aunque se había producido una vulneración de los derechos a la intimidad y la vida privada de los demandantes y se reconocía que con el tiempo el interés de la persona en que no sea vinculada con los hechos iba ganando peso, la identificación de los recurrentes en los reportajes estaba justificada cuando el interés del público en conocer la verdad era mayor que el perjuicio causado. Para ponderar los derechos en liza, el Tribunal tuvo en cuenta la forma en la que las personas en cuestión fueron presentadas en las noticias y, en particular, su grado de difusión. Asimismo, la gravedad del delito y su repercusión entre el público, la notoriedad de la víctima y el hecho de que los condenados se expusieran ante la prensa llevaron al Tribunal Federal a considerar que con su propia actuación los hermanastros dotaron de nuevo a los hechos de un carácter noticiable. Además, alertó de que la imposición de una obligación a la prensa de control periódico de sus archivos, con la consecuente inversión en tiempo y dinero que ello supondría, podría desincentivarla a mantener sus hemerotecas digitales, pese a la importancia de estos archivos para satisfacer el interés del público por obtener informaciones antiguas.

Finalmente, y tras la inadmisión de los recursos presentados por los titulares de los datos ante el Tribunal Constitucional alemán por cuestiones procesales, recurrieron ante el TEDH por vulneración del derecho a la vida privada del art. $8 \mathrm{CEDH}$, en el que se incardina el derecho a la protección de los datos personales ${ }^{16}$, dictándose sentencia al respecto el 28 de junio de

16 Así lo declaró el TEDH ya en su sentencia de 26 de marzo de 1987, TEDH 1987/4, caso Leander c. Suecia, en la que se consideró que la inclusión de datos personales y de 
2018 en el caso M. L. y W. W. c. Alemania. Tras destacar las funciones de la prensa, la primaria como "perro guardián» de la opinión pública y la secundaria o accesoria de los archivos digitales como mecanismo de preservación de la información, el Tribunal tuvo en cuenta una serie de criterios a la hora de ponderar los derechos a la vida privada de los recurrentes y el de la libertad de expresión de la prensa (art. $10 \mathrm{CEDH})$. En primer lugar, señaló que, pese al transcurso del tiempo, las noticias en cuestión seguían contribuyendo al debate público, dada la gravedad de los hechos y la notoriedad de la víctima, además de que las mismas recogían información veraz. En este sentido, el TEDH recordó la necesidad de "hacer gala de la máxima prudencia» a la hora de establecer sanciones o medidas a la prensa que puedan disuadirla de conservar y poner a disposición del público sus archivos digitales, como podría ser la obligación de examinar en un estado posterior la legalidad de un reportaje a petición del interesado, pues ello iría en detrimento del derecho de los ciudadanos a obtener informaciones antiguas (párr. 105). En segundo lugar, llegó a la conclusión de que los involucrados, pese a ser particulares, no podían ser considerados como simples personas privadas, pues adquirieron relevancia pública por razón del objeto de la noticia, el asesinato de un actor (párr. 106). En tercer lugar, el Tribunal valoró la conducta previa de los recurrentes y puso de relieve que, además de presentar todos los recursos posibles, uno de ellos se dirigió a la prensa para mantener informado al público sobre su demanda de revisión del caso, e incluso en 2006, la página web de su abogado tenía publicada información al respecto (párr. 108). En consecuencia, entendió que los hermanastros solo podían tener «una expectativa legítima limitada [...] a esperar el anonimato en los reportajes, es decir, un derecho al olvido digital» (párr. 109). Por último, el TEDH determinó que la información presentaba los hechos de forma objetiva y declaró que los recurrentes no se habían dirigido en ningún momento a los buscadores para limitar la accesibilidad a las noticias. Por todo ello, consideró que el Tribunal Federal de Justicia alemán no había faltado a las obligaciones del Estado en relación con el art. 8 del CEDH.

carácter político de una persona en el fichero del Registro de Seguridad de la Policía Nacional sueca constituía una interferencia en el derecho a la vida privada reconocido en el art. 8 CEDH. En el mismo sentido, y entre las más recientes, véanse SSTEDH de 5 de septiembre de 2017, TEDH/2017/61, caso Barbulescu c. Rumanía, y de 9 de enero de 2018, TEDH/2018/1, caso López Ribalda y otros c. España. Sobre la inclusión de la protección de datos en el derecho a la vida privada del art. $8 \mathrm{CEDH}$, véase De Vries (2018: 672-678). 


\section{LAS HEMEROTECAS DIGITALES DE LA PRENSA Y SUS FUNCIONES}

En la actualidad, casi la totalidad de las páginas web tiene una hemeroteca, esto es, un archivo en el que se pueden consultar los registros o contenidos de fechas anteriores, desde un blog o red social, pasando por una revista o un periódico digitales, hasta las páginas oficiales de organismos públicos. Ahora bien, conviene reparar en que nuestro estudio está limitado al conflicto entre el derecho al olvido y la libertad de información cuando esta es ejercitada por un colectivo concreto: la prensa. Y la puntualización no es baladí, pues a la hora de poner en la balanza los derechos en liza habrá que tener en cuenta que la libertad de información «alcanza su máximo nivel cuando la libertad es ejercitada por los profesionales de la información ${ }^{17}$ ».

En este contexto, y dado que existe una protección específica de la citada libertad en estos casos, conviene analizar y acotar el propio concepto de "prensa» y el de su «hemeroteca». De este modo será posible conocer el alcance real de la controversia y podremos adentrarnos en la difícil tarea de ponderar el conflicto entre el derecho al olvido y la libertad de información, cuando la misma se refiere a noticias del pasado.

17 STC 165/1987, de 27 de octubre, ECLI:ES:TC:1987:165, FJ 10. La razón que lleva al TC a realizar tal afirmación es que «la libertad de información es, en términos constitucionales, un medio de formación de opinión pública en asuntos de interés general, cuyo valor de libertad preferente sobre otros derechos fundamentales y entre ellos el derecho al honor, [...] viene determinado por su condición de garantía de la opinión pública, que es una institución constitucional al Estado democrático que los poderes públicos tienen especial obligación de proteger». Dicha consideración es reiterada, entre otras, en la STC 225/2002, de 9 de diciembre, RTC/2002/225, en la que se aclara que la protección específica de la libertad de información en el caso de los profesionales de la información se debe a que «tal libertad no integra solamente un derecho subjetivo de aquéllos, sino también una garantía de la formación de una opinión pública libre» (FJ 4). En el mismo sentido, el TEDH destaca en su sentencia de 10 de marzo de 2009, JUR/2009/100304, caso Times Newpapers Ltd ( $n .^{\circ} 1$ y 2) c. Reino Unido, la importancia de la libertad de expresión como fundamento esencial de una sociedad democrática, siendo especialmente importante garantizar la libertad de la prensa, pues ello permite que también se asegure el derecho de los ciudadanos a la información. Por ello, señala el Tribunal que cualquier medida que afecte a la prensa $y$, consecuentemente, al derecho a la información, debe estar fundada en «argumentos de peso» (párrs. 40 y 41). En cuanto a ello, señala Lazkano Brotóns (2015: 542): «La libertad de prensa se beneficiaría así de un estatuto jurídico reforzado y en ella el margen nacional de apreciación se reduce o, lo que es lo mismo, el control del TEDH sobre las injerencias producidas se intensifica». 
En cuanto a ello, cabe destacar que el TJCE exige una interpretación amplia de todos los conceptos relacionados con la libertad de expresión, entre los que destaca el de periodismo ${ }^{18}$, lo que se ha visto reflejado en el considerando $153 \mathrm{RGPD}^{19}$. Así, lo determinante es que la actividad tenga "fines exclusivamente periodísticos», esto es, que su finalidad sea la de divulgar información al público, independientemente de que la misma sea desarrollada o no por empresas dedicadas a este sector y se lleve a cabo con ánimo de lucro o a título gratuito $^{20}$. Asimismo, se admite el carácter periodístico de la actividad independientemente del soporte en el que tenga lugar, desde los clásicos como el papel o la radio hasta el más reciente como internet ${ }^{21}$, lo que resulta acorde con la precisión del art. 20.1 d) CE cuando establece que la comunicación de información veraz puede tener lugar "por cualquier medio de difusión». Dicho esto, podemos definir el periodismo como el conjunto de empresas, ya sean editoriales, radiofónicas o productoras audiovisuales, y de profesionales independientes dedicados a la difusión de información veraz por cualquier medio físico o digital ${ }^{22}$. De este modo, es posible adecuar el concepto de prensa a los nuevos entornos en los que esta se desarrolla, como a través de las redes sociales. Así, debe abarcar tanto el periódico digital como el Twitter, blog o Facebook de las empresas de comunicación y de los profesionales de la información freelance cuando utilicen estas plataformas con una finalidad periodística.

18 STJCE, de 16 de diciembre de 2008, asunto C-73/07, TJCE/2008/315, caso Satakunnan, párr. 56.

19 Según el mismo: «A fin de tener presente la importancia del derecho a la libertad de expresión en toda sociedad democrática, es necesario que nociones relativas a dicha libertad, como el periodismo, se interpreten en sentido amplio».

20 Caso Satakunnan, párrs. 60 y 61. En cuanto a ello, Arenas Ramiro (2013: 367) considera que incluso los SMS informativos deben quedar comprendidos en el concepto de prensa. Cabe destacar que el considerando 121 de la Propuesta de RGPD de 2012 venía a reproducir de forma casi literal lo señalado por el TJCE en dichos párrafos. No obstante, se ha eludido todo intento de definición de "periodismo» en el finalmente aprobado considerando 153 RGPD, lo que lamenta Pazos Castro (2016: 40).

21 Caso Satakunnan, párr. 60.

22 De forma similar, la STC de 4 de junio de 2018 señala en su FJ 7 que «[...] la garantía de las libertades informativas se vincula a la actividad de los medios de comunicación, debiendo integrarse en esta denominación tanto la prensa escrita, radio y televisión, sea cual sea el soporte a través del cual se difunda su actividad periodística, como los medios de comunicación exclusivamente digitales. Todos ellos desempeñan un papel innegable, en orden a garantizar la plena eficacia del pluralismo, como valor superior del ordenamiento [...]». 
Ahora bien, no todo lo que publica la prensa es el resultado del ejercicio de la libertad de información, sino que es frecuente que, en un diario, por ejemplo, se incluyan secciones como la de los «artículos de opinión», en las que es la libertad de expresión la que justifica la publicación ${ }^{23}$. Asimismo, un periódico digital o las noticias de un canal de televisión incluyen publicidad que sirve a los efectos de financiar la prensa y promocionar el producto o servicio de que se trate, pero no de informar a la sociedad. Siendo ello así, la especial protección que confiere la libertad de información a la prensa debe aplicarse únicamente a las noticias en las que se comunica información veraz de carácter "noticiable» o "noticioso», esto es, la que versa sobre hechos «que puedan encerrar trascendencia pública y que sean necesarios para que sea real la participación de los ciudadanos en la vida colectiva", tal y como se define la libertad contenida en el art. 20.1 d) CE por el TC ${ }^{24}$. No genera dudas el hecho de que la prensa necesita tratar datos personales, como el nombre y apellidos o ciertas fotografías ${ }^{25}$, de las personas que se ven involucradas en un hecho noticiable o suceso de actualidad. En estos casos, el ejercicio de la libertad de información justifica dicho tratamiento sin necesidad de contar con el consentimiento de los titulares de los datos ${ }^{26}$.

23 De forma similar, Arenas Ramiro (2013: 366) señala que no toda la información que se encuentra en internet tiene valor informativo.

24 STC 105/1983, de 23 de noviembre, ECLI:ES:TC:1983:105, FJ 11. Véanse, en especial, en cuanto al contenido de la libertad de información y su distinción con la de expresión, las SSTC 57/1999, de 12 de abril, RTC/1999/57, FJ 7, y 126/2003, de 30 de junio, RTC/2003/126, FJ 3, así como la SAN de 29 de diciembre de 2014, JUR/2015/26978, FD 8. En el mismo sentido, Cotino Hueso (2010: 309) afirma que lo que no sea información veraz no está protegido por la libertad de información.

La propia definición de «datos personales» contenida en el art. 4.1) RGPD contempla el nombre como un tipo de dato personal. De modo que no resulta necesario analizar tal concepto en este estudio.

26 Ello es así porque normalmente las informaciones que mayor valor tienen para la sociedad son a las que dichos titulares quieren que se les dé la menor difusión posible (Arias Máiz, 2010: 565). Exigir al periodista que solicite autorización para usar los datos de una persona por un hecho que podría perjudicar su imagen o reputación supondría tanto como impedir al primero ejercer su profesión, limitando su libertad de comunicar información veraz y el derecho de todos los ciudadanos a recibirla. De ahí que el art. 6.1 f) RGPD recoja la necesidad del tratamiento de datos "para la satisfacción de intereses legítimos perseguidos por el responsable del tratamiento o por un tercero" entre las causas que legitiman un tratamiento de datos sin el consentimiento de su titular. Una redacción similar contenía el derogado art. 6.2 LOPD. En cambio, el art. 8 LOPDGDD, precepto regulador de dichas causas, parece limitar los supues- 
En cuanto a las hemerotecas, el DRAE las define como «bibliotecas en que principalmente se guardan y sirven al público diarios y otras publicaciones periódicas». Esta explicación reduce su alcance al archivo de los tradicionales periódicos o revistas. No obstante, consideramos que es necesario y posible adaptar esta definición al concepto de prensa defendido en el presente trabajo ${ }^{27}$. De este modo, y a nuestro juicio, la hemeroteca digital de la prensa debe incluir tanto los apartados específicos así denominados en las páginas web de las empresas de comunicación como los archivos de entradas, ya sean de texto, audio o audiovisuales, de las redes sociales, blogs o canales de Youtube, por ejemplo, en los que tales empresas y otros profesionales de la información independientes desarrollen su actividad periodística, pese a las dudas que al respecto ha manifestado López Calvo (2018: 5).

Pues bien, aunque está justificado que no se requiera el consentimiento de los titulares de los datos de las personas que participan en un hecho noticiable cuando la prensa informa sobre un hecho de actualidad, la certidumbre se desvanece cuando la prensa digitaliza toda la información que ha publicado con anterioridad y la archiva de forma digital, permitiendo el acceso a su contenido a los internautas. Se trata, pues, de un nuevo tratamiento de datos personales ${ }^{28}$, pero en relación con noticias que ya no son novedosas, pues pertenecen a un pasado más o menos reciente. Precisamente el transcurso del

tos en los que no se requiere autorización del titular de los datos para su tratamiento a los casos de cumplimiento de una obligación legal del responsable del tratamiento o misión realizada en interés público o en el ejercicio de poderes públicos, previstos en los literales c) y e) del art. 6.1 RGPD a los que remite. Aunque consideramos que esta disposición podría generar dudas en cuanto a la legitimidad del uso de datos por parte de la prensa sin el consentimiento de sus titulares, la mala técnica legislativa en este aspecto no empece que se aplique directa y preferentemente el art. 6.1 f) RGPD sobre la legislación interna. Lo que nos cuestionamos es hasta qué punto puede considerarse acorde el art. 8 LOPDGDD con la norma europea. En este sentido, el cambio de la directiva al reglamento como instrumento legislativo europeo para regular esta materia debe ser valorado positivamente, pues solo así será posible alcanzar un auténtico marco común y uniforme de protección de los datos personales de los ciudadanos de la UE. En el mismo sentido se manifiesta Di Pizzo Chiacchio (2018: 245).

27 Como señala Simón Castellano (2015: 282), el concepto de hemeroteca ha cambiado radicalmente a raíz de la creación de archivos digitales.

28 La publicación de datos personales en páginas web constituye un tratamiento de datos de acuerdo con la STJCE, de 6 de noviembre de 2003, asunto C-101/01, TJCE/2003/368, caso Lindqvist, párrs. 24-27. En cuanto a ello, Cotino Hueso (2010: 300) señala que la hemeroteca virtual no es en sí el medio de comunicación, sino que se opera un tratamiento diferente a partir de fuentes accesibles. 
tiempo hace que pierdan su carácter noticiable o trascendencia pública, en especial cuando las personas a las que se refieren son particulares. En este contexto, nos hacemos la siguiente pregunta: ¿la nueva publicación, y con ella, el nuevo tratamiento de datos que realiza la prensa cuando digitaliza y pone a disposición del público noticias que ya no son actuales, puede considerarse amparada por la libertad de información, la de expresión o la propiedad intelectual, por ejemplo? En función de la respuesta que demos a esta cuestión, los criterios de ponderación para equilibrar el conflicto con el derecho a la protección de datos pueden variar considerablemente.

En este punto, resulta fundamental destacar lo señalado por el TEDH en la sentencia que resuelve el caso Times Newpapers Ltd ( $n^{o} 1$ y 2$)$ c. Reino Unido, que además conecta con las funciones de la prensa y sus hemerotecas en la sociedad ${ }^{29}$. De acuerdo con el párr. 45 de dicha resolución, «[...] aunque la función principal de la prensa en una sociedad democrática es actuar como "perro guardián", también desempeña una valiosa labor secundaria consistente en mantener y hacer accesibles al público los archivos de noticias previamente publicadas». De este modo, el TEDH confiere a la prensa una doble función: la primaria, que se corresponde con la contribución a la formación de una opinión pública libre por medio de la publicación de noticias de actua$\operatorname{lidad}^{30}$, y la secundaria, aunque, en palabras de dicho tribunal, "valiosa ${ }^{31}$, que coadyuva a la educación y la investigación histórica y se consigue mediante el mantenimiento de archivos o hemerotecas accesibles al público que contienen las noticas previamente publicadas.

29 Los hechos que dieron lugar al conflicto se remontan a la publicación en 1998 en el diario The Times de una noticia sobre un caso de blanqueo de dinero relacionado con un presunto capo de la mafia rusa, identificado con nombre y apellidos, que, además, dirigía una empresa asociada al primer ministro ruso del momento, noticia que fue seguida de otra publicación sobre la misma investigación en 1999. Este último año, el diario incorporó ambas noticias en su página web y el implicado interpuso demanda por difamación contra el periódico, su editor y los periodistas que firmaban los artículos.

30 Sobrela misma, véanseSSTEDH39954/08, de 7 de febrero de 2012, JUR/2012/46200, caso Axel Springer Agc. Alemania, párr. 78, y de 24 de junio de 2004, TEDH/2004/45, caso Von Hannover c. Alemania, párr. 58.

31 De acuerdo con la narración de los hechos llevada a cabo por el TEDH en este caso, cuando el asunto llegó ante la Court of Appeal, esta coincidió con el argumento del diario The Times en que el mantenimiento de archivos tiene una utilidad social. No obstante, y a diferencia del carácter "valioso» que les confiere el TEDH, la Corte afirmó que «[...] the maintenance of archives is a comparatively insignificant aspect of freedom of expression» (párr. 16). 
Aunque ciertamente ello no supone afirmar que la nueva publicación de informaciones antiguas para su inclusión en estas hemerotecas esté amparada por la libertad de expresión del art. $10 \mathrm{CEDH}$, el TEDH sí señala que el margen de apreciación que corresponde a los Estados a la hora de ponderar los derechos enfrentados es mayor en el caso de archivos sobre hechos pasados que cuando se trata de noticias de actualidad (párr. 45). De esta consideración se deriva que el citado tribunal considera que el contenido de las hemerotecas digitales de la prensa puede dar lugar a infracciones de ciertos derechos de las personas, pues su publicación no puede tener como efecto directo la supresión de la información posiblemente vulneradora de los mismos, sino que es necesario llevar a cabo un ejercicio de "ponderación de derechos». En consecuencia, estos archivos digitales están amparados por el art. $10 \mathrm{CEDH}$, que reconoce la libertad de expresión en sentido amplio, como inclusiva de la de información. En nuestra opinión, además, esta protección resulta esencial para asegurar la formación de la opinión pública futura, pues la mayor parte de la información que se publica en la actualidad ya no se puede encontrar en versión tangible. En un periódico, por ejemplo, aunque cada día se edite un ejemplar en papel, la versión online actualiza constantemente la información, no incluyéndose esta, por tanto, en la publicación física. Lo mismo sucede en relación con las redes sociales empleadas por la prensa para ejercer la libertad de información. Así, la protección que otorga el TEDH a las hemerotecas, entendiéndolas como se ha descrito previamente, salva la situación de la posible pérdida de la información no sujeta al deber de depósito previsto en la Ley 23/2011, de 29 de julio, de depósito legal.

No obstante, la mayor libertad otorgada por el citado tribunal a los Estados a la hora de equilibrar los derechos en liza en relación con las hemerotecas refleja la menor intensidad con la que la libertad de información se manifiesta a través de las noticias antiguas. En cuanto a ello, el TC, en el caso objeto de estudio, ha colegido de las palabras del tribunal europeo que «[...] si bien ambas [las funciones de la prensa] desempeñan una función notable en la formación de la opinión pública libre, no merecen un nivel de protección equivalente al amparo de la protección de las libertades informativas, por cuanto una de las funciones es principal y la otra secundaria» (FJ 7). En línea con la posible menor protección de este derecho en los supuestos de hemerotecas digitales, el tribunal europeo establece que el nivel de diligencia exigible a la prensa en relación con la exactitud de los hechos pasados debe ser más estricto o elevado que cuando la actualidad de los hechos exige que la noticia sea publicada de forma inminente (párr. 45) 32 .

32 Sobre ello, véase Rallo (2014: 212-213). 
Reconocida la protección de las informaciones pasadas por la libertad del art. $10 \mathrm{CEDH}$ y el art. $20.1 \mathrm{~d}$ ) $\mathrm{CE}$, podemos concluir que tampoco en los supuestos de publicación de noticias en los archivos digitales se requiere el consentimiento del titular de los datos, pues dicho tratamiento será necesario «para la satisfacción de intereses legítimos perseguidos por el responsable del tratamiento o por un tercero" (art. 6.1f RGPD) ${ }^{33}$. Además, este argumento permite sostener que el nuevo tratamiento consistente en la inclusión de la noticia en la hemeroteca no persigue una finalidad nueva y distinta de la que justificó su recogida inicial, pues seguirá siendo la de la libertad de información, si bien en relación con una función secundaria de la prensa. De ahí que el TS afirmara en su sentencia de 15 de octubre de 2015 que las hemerotecas digitales son un bien jurídico amparado por la libertad de información, respecto del que no cabe alterar su contenido, pues la misma protege su «integridad $^{34}$ ». Asimismo, el TC no concedió a las recurrentes en amparo la medida solicitada consistente en la supresión de sus nombres y apellidos de la noticia o, subsidiariamente, su sustitución por sus iniciales. En el mismo sentido, la STEDH, de 16 de julio de 2013, caso Wegrzynowski y Smolczewski c. Polonia, vino a señalar que «no corresponde a las autoridades judiciales participar en reescribir la historia» (párr. 65) ${ }^{35}$. En esta línea, cuando se ha solicitado tutela de los derechos previstos en la LOPD a la AEPD frente a la prensa, aunque se le ha recomendado que implemente comandos noindex o nofollow en relación con noticias antiguas, en ninguna resolución se le ha exigido ni aconsejado que el nombre y apellidos de los particulares fueran eliminados o sustituidos por sus iniciales ${ }^{36}$.

33 En cuanto a esta cuestión, en el caso Mosley c. Reino Unido, resuelto por la STEDH de 10 de mayo de 2011, TEDH 2011/45, el Tribunal consideró que el establecimiento de una obligación de notificación previa a la publicación de informaciones, aunque en el supuesto concreto serviría para evitar la difusión de una información sensacionalista, como lo era el vídeo de una orgía del solicitante, podría afectar gravemente a la libertad de expresión si se extendiera al periodismo serio (párr. 121). De la misma opinión se muestra Arias Máiz (2010: 574), al señalar que, si no se admitiera la publicación de noticias antiguas sin autorización de los titulares de los datos, se haría casi impracticable el periodismo de investigación.

34 En contra, Berrocal Lanzarot (2017: 192-193) considera que, en el caso resuelto por el Tribunal, tendría que haberse adoptado la medida establecida en la sentencia de apelación, esto es, el cese en el uso del nombre y apellidos en la noticia. JUR/2013/252862.

36 Como ejemplos, cabe citar, precisamente, las resoluciones n.o R/00085/2010 y n. ${ }^{\circ} \mathrm{R} / 00094 / 2010$, referidas al caso que finalmente fue resuelto por el TC y que es objeto de análisis en el presente trabajo. 
En cuanto a ello, resulta conveniente retomar de nuevo aquí la idea de que no todo lo que es publicado por la prensa es información protegida por la libertad de información, como, por ejemplo, la publicidad o los artículos de opinión. Así, entendemos que en estos casos la «integridad» que se predica de las hemerotecas no debe referirse al archivo digital como tal, sino que ha de aplicarse a las noticias antiguas que aportaban información veraz y trascedente para la sociedad y que ahora se contienen en el mismo. De este modo, no cabría sostener la protección de la integridad de los contenidos de finalidad no periodística publicados por la prensa en el pasado, debiendo analizarse caso por caso si el tratamiento en cuestión resulta proporcionado o no. En consecuencia, y a nuestro juicio, en el denominado caso Google no era la libertad de información lo que ejercitaba el periódico La Vanguardia cuando hacía el anuncio de la subasta del inmueble del señor Mario Costeja, sino que cumplía una orden del Ministerio de Trabajo para dar la mayor difusión posible a tal hecho. Así, coincidimos con Brotons Molina (2013: 124-125) en que el mantenimiento del nombre y apellidos en dicha nota de prensa resulta excesivo en relación con la finalidad para la que fueron recogidos, pues ya se había cumplido con la misma, la publicidad del acto administrativo en cuestión, y se había resuelto la deuda que originó el embargo. A lo que añadimos que, al no ser la libertad de información la que motivó en origen su publicación ${ }^{37}$, no se puede concluir que con la inclusión de dicho anuncio en la hemeroteca se esté dando cumplimiento a la función secundaria de dicha libertad, que es la que justifica la protección de la integridad del contenido de la publicación antigua.

Ahora bien, no siendo necesario el consentimiento de los titulares de los datos en estos casos, cuando la noticia antigua se refiere a hechos no especialmente graves, como pudiera ser la pintada de una estatua durante la juven$\operatorname{tud}^{38}$, en los que intervienen sujetos sin relevancia pública, el transcurso del

37 Lo mismo entiende Rallo (2014: 241-242).

38 Un caso similar a este fue resuelto por la AEPD por medio de la Resolución n. ${ }^{\circ} \mathrm{R} / 1509 / 2009$. En el asunto en cuestión, varios periódicos publicaron en 2004 en su versión digital una noticia sobre la condena a un joven de 21 años por la rotura de la mano del monumento de la Cibeles en Madrid. Aunque no se dirigió contra los webmaster, esto es, contra los periódicos que mantenían dicha información en sus hemerotecas, el implicado ejerció su derecho de oposición al tratamiento ante la AEPD para que Google desindexara su nombre y apellidos, pues, ya cancelados sus antecedentes penales, el posible acceso a esta noticia a través del buscador le ocasionaba un importante perjuicio personal y profesional. Finalmente, la Agencia estimó la reclamación porque, aunque no era prolongado el tiempo transcurrido, los efectos que podía provocar la indexación de la noticia en la vida laboral del reclamante por 
tiempo hace que la trascendencia de la información se diluya. No obstante, la gran difusión que internet puede dar a tales hechos y la pérdida de control de la información por parte del involucrado en la misma pueden afectar negativamente a la reputación de la persona, impidiéndole desarrollar su proyecto vital. Por ejemplo, en relación con el supuesto resuelto por el TC, ¿confiaría un particular en la contratación de una abogada o asistiría a la consulta de una doctora respecto de la que hay una noticia que la vincula con una red de tráfico de drogas que aparece entre los primeros resultados de Google cuando se buscan su nombre y apellidos? Probablemente no, incluso aunque la noticia fuera de los años ochenta.

En relación con este contexto, las TIC han alterado el devenir natural de la memoria colectiva, pues mientras la memoria humana es limitada y la persona necesita desechar los errores del pasado para poder sobreponerse y avanzar, internet no olvida ${ }^{39}$. Es precisamente en este contexto en el que nace y se necesita el denominado derecho al olvido. En cualquier caso, no se puede exigir a la prensa que solicite autorización a todos los titulares de todos los datos que la misma trata para incluir noticias que fueron publicadas lícitamente en sus hemerotecas, es decir, no se puede establecer un mecanismo de control y protección del derecho al olvido ex ante. Aunque autores como Aberasturi Gorriño (2016: 13) estén en contra de esta consideración ${ }^{40}$, sostenemos con parte de la doctrina que pese a los riesgos derivados de que el derecho se deje a instancias del interesado, los mismos provocan un daño mucho menor en este que el que generaría la imposición de ese control previo, como la desincentivación de los medios a conservar sus archivos digitales ${ }^{41}$. Ahora bien, el titular de los datos debe tener el derecho a reaccionar u oponerse a dicho tratamiento cuando el transcurso del tiempo haya provocado que el ejercicio de la libertad

unos hechos de la «juventud» serían especialmente gravosos. Comenta ese asunto Rallo (2014: 125-126).

39 Como afirmó la comisaria comunitaria de Justicia de la Unión Europea, «Dios perdona y olvida, pero la web, nunca», según señala la SAP Barcelona 486/2013, de 11 octubre, AC/2013/1921, FD 4.

40 En concreto, afirma que el responsable del tratamiento de los datos debe activar motu proprio el derecho al olvido cuando los datos hubieran dejado de cumplir con el principio de calidad de los datos. No tiene en cuenta el autor, no obstante, que el análisis de tal circunstancia habría de llevarse a cabo en relación con las ingentes cantidades de información que se generan diariamente, lo que podría suponer, en caso de que la valoración se hiciera con poco rigor por las exigencias de la inmediatez que caracteriza internet, una restricción desproporcionada de la libertad de información.

41 En este sentido, entre otros, Seligrat González (2015: 3), Pazos Castro (2016: 14) y Simón Castellano (2015: 285). 
de información para la consecución de su función secundaria suponga un sacrificio desproporcionado de los derechos de la personalidad protegidos por medio del derecho a la protección de datos y, en concreto, a través del derecho al olvido.

\section{LA FRONTERA ENTRE EL DERECHO AL OLVIDO Y LA LIBERTAD DE INFORMACIÓN. CRITERIOS PARA SU DELIMITACIÓN Y MEDIDAS DE RESTABLECIMIENTO DEL DERECHO AL OLVIDO}

Centrándonos, pues, en el conflicto entre el derecho al olvido y la libertad de información ${ }^{42}$, el TC y el TEDH aplican, con acierto, los mismos criterios de valoración que los que vienen empleando cuando la libertad informativa se enfrenta a otros derechos de la personalidad como el honor o la intimidad $^{43}$. Ahora bien, aportan matices a su doctrina previa para adaptarla a las particularidades derivadas de la apreciación del derecho al olvido y de la función secundaria de la prensa en relación con las hemerotecas digitales ${ }^{44}$.

42 Aunque, como hemos señalado, también se alegó la vulneración de los derechos al honor y a la intimidad en el asunto resuelto por el TC, nuestro estudio se limita al conflicto entre la libertad de información y el derecho al olvido fundamentalmente por dos razones. En primer lugar, porque es la valoración de este derecho la que hace que el TC admita el recurso. Y, en segundo, porque la argumentación tanto del TS como del TC se sustenta sobre la normativa protectora de los datos personales. De hecho, las resoluciones en cuestión únicamente realizan el análisis de ponderación de derechos en relación con el derecho al olvido y, considerado vulnerado este, se presume por los citados tribunales que se produce una intromisión ilegítima en el honor y la intimidad de las recurrentes. Por ello, la relevancia del caso en cuestión se encuentra en la virtualidad del derecho a la protección de datos y, en concreto, en el derecho al olvido como instrumento de garantía del honor y la intimidad. En cuanto a ello, Aberasturi Gorriño (2016: 4) critica que el TS no determinara con claridad qué derechos resultaban vulnerados en el caso.

La misma valoración positiva realiza Arias Máiz (2010: 570).

44 En relación con ello, el TJUE ha señalado en varias ocasiones que es necesario llevar a cabo una ponderación de los derechos en estos casos, si bien han sido pocas las pistas que ha aportado a los juzgadores nacionales para acometer dicha tarea y ello pese a que, a diferencia del TEDH, sí cuenta con un reconocimiento expreso de la protección de datos como derecho fundamental en el art. 8 CDFUE. Así, en el caso Lindqvist, el TJCE afirmó que «[...] el justo equilibrio entre los derechos e intereses en juego debe buscarse más bien en el ámbito nacional [...]» (párr. 85), y para ello, los jueces nacionales llevarán a cabo un ejercicio de ponderación en el que deberán tenerse en cuenta la duración de la infracción de las normas protectoras de los datos 
Así, debemos comparar el interés perseguido por la prensa con el tratamiento de los datos y la injerencia que provoca dicho tratamiento en los derechos del interesado por los contenidos de las hemerotecas para lograr un equilibrio que garantice la proporcionalidad entre finalidad e injerencia. En este contexto, tradicionalmente se ha otorgado un carácter preferente, que no jerárquico, a las libertades informativas sobre los derechos de la personalidad en los supuestos en los que la información es veraz, tiene relevancia pública y no contiene expresiones vejatorias o innecesariamente ofensivas, esto es, teniendo en cuenta cómo es presentada la noticia ${ }^{45}$. En cuanto a este último criterio, lo cierto es que si la noticia presentaba los hechos de manera insultante cuando se publicó, normalmente el afectado reaccionaría en ese momento, pues es cuando mayor difusión tiene la información y, por tanto, cuando mayor puede ser la afectación de su honor. Por ello, este elemento es el que menos problemas plantea en relación con el derecho al olvido digital y no será analizado de forma concreta ${ }^{46}$. Pasemos, pues, a valorar los criterios

personales y la importancia para los afectados de la tutela de los datos difundidos (párrs. 88 y 89). La misma remisión a las autoridades nacionales llevó a cabo el Tribunal en el caso Promusicae, en el que la protección de datos se enfrentaba al derecho de propiedad intelectual (STJCE de 29 de enero de 2008, asunto C-275/06, TJCE/2008/11), y en el caso Rijkeboer, referido a la protección de datos y el derecho a la información (STJCE de 7 de mayo de 2009, asunto C-553/07, TJCE/2009/119). En el caso Google, el TJUE simplemente señaló que en la ponderación de los intereses en juego debe tenerse presente que la injerencia en el derecho a la vida privada puede ser mayor cuando el tratamiento se lleva a cabo por un buscador que cuando el mismo lo realiza el webmaster o editor de la información en la página web (párr. 87). Por tanto, serán la jurisprudencia del TC y la del TEDH las que sirvan en mayor medida para resolver el conflicto en cuestión.

45 Estos son los elementos valorados por el TC (FJ 7) y el TEDH (párr. 95) en las sentencias que justifican este trabajo, siguiendo su doctrina previa. Destacan en este sentido, entre otras, las SSTC 320/1994, de 28 noviembre, RTC/1994/320; de 31 enero, RTC/2000/21, y 216/2006, de 3 julio, RTC/2006/216. En cuanto a la atribución de protección preferente a la libertad de información en abstracto y su crítica, véase De Verda y Beamonte (2015: 393-394).

46 De hecho, en relación con los supuestos estudiados, el TEDH se limitó a señalar que los artículos que habían sido cuestionados no reflejaban una intención de presentar a los hermanastros de forma despectiva, ni que tampoco empleaban expresiones que pudieran afectar a su reputación (párr. 111). De este modo, las noticias habían sido difundidas mediante el relato objetivo de los hechos. Por su parte, el TC y el TS no valoraron este aspecto, deteniendo su análisis sobre la ponderación de derechos en la relevancia pública de la información. 
determinantes para resolver el conflicto: la veracidad de la información y su relevancia pública.

\section{LA VERACIDAD DE LA INFORMACIÓN}

El TC ha señalado en numerosas ocasiones que la veracidad de la información no equivale a que la misma sea completamente exacta o correcta, sino que sea el resultado de una investigación diligente por parte del profesional de la prensa ${ }^{47}$. En relación con ello, las sentencias de primera y segunda instancia del asunto español que nos ocupa concluyeron que, con el transcurso del tiempo, la información había dejado de ser veraz, puesto que los antecedentes penales habían sido cancelados y las hermanas habían superado su drogadicción ${ }^{48}$. En cambio, y con mayor acierto, el TS y el TC consideraron que el factor tiempo no influía en la veracidad o no de la noticia, pues, de hecho, en ningún momento del procedimiento se alegó que la misma no se correspondiera con los hechos acaecidos ${ }^{49}$. En efecto, aunque en el principio de calidad de los datos se incluye la necesidad de que los mismos sean exactos $y$, en su caso, actualizados ${ }^{50}$, en ningún momento se oculta al internauta que los datos se refieren a una situación del pasado. De hecho, cuando la información es buscada por el usuario de la hemeroteca sabe que está accediendo a un archivo que recoge noticias antiguas y que la situación actual de las personas involucradas en las mismas probablemente haya cambiado, en especial si ha

47 Entre otras, véanse SSTC 21/2000, de 31 de enero, ECLI:ES:TC:2000:21, FJ 5; 126/2003, de 30 de junio, RTC/2003/126, FJ 3; 216/2006, de 3 de julio, RTC/2006/216, FJ 8; 129/2009, de 1 de junio, RTC/2009/129, FJ 2, y STS, Sala Primera, 362/2016, de 1 junio, RJ/2016/2323, FD 5. Asimismo, en un caso relativo al derecho al olvido, el TS ha señalado que «[...] la regla constitucional de la veracidad constituye una garantía frente al informador que transmite como verdaderos simples rumores sin contrastar o meras invenciones, pero, por el contrario, no llega al extremo de imponer un deber de exactitud, sino el deber de contrastar previamente la noticia mediante fuentes objetivas, fiables, identificables y susceptibles de contraste [...]» (STS, Sala Primera, 426/2017, de 6 julio, RJ/2017/3194, FD 3). En el mismo sentido, De Verda y Beamonte (2015: 395) y Arias Máiz (2010: 569).

48 Sentencia del Juzgado de Primera Instancia de Barcelona, 156/2012, de 4 octubre, AC/2014/856, FD 6, y SAP Barcelona, 486/2013, de 11 octubre, AC/2013/1921, FD 5. Del mismo parecer se muestra Aberasturi Gorriño (2016: 14).

49 STS, Sala Primera, 545/2015, de 15 de octubre de 2015, RJ/2015/4417, FD 4, y STC 58/2018, de 4 de junio de 2018, RTC/2018/58, FJ 8.

50 En el momento de la resolución del caso, era aplicable el art. 4.3 LOPD, que en la actualidad se corresponde con los arts. 4.1 LOPDGDD y 5.1 d) RGPD. 
transcurrido un importante período de tiempo. Además, la consideración de los juzgadores de instancia y apelación daría lugar a que toda la información contenida en las hemerotecas digitales resultara inveraz, pues la situación de las personas involucradas en noticias del pasado habrá cambiado por el simple transcurso del tiempo. Así, la noticia es veraz cuando el profesional de la información cumple con el nivel de diligencia exigible en el ejercicio de su actividad periodística al publicarla, al margen de que lo relatado se corresponda por completo o no con la realidad de los hechos tanto en el momento de la publicación como en la actualidad ${ }^{51}$.

Ahora bien, incluso aun habiendo sido aplicada la diligencia propia del periodismo, puede suceder que la noticia recoja hechos que, siendo ciertos en el momento de la publicación y pudiendo afectar a la reputación de la persona, finalmente resulten erróneos, inexactos o requieran una aclaración. Póngase por caso la noticia en la que se informa de la detención de una persona por presunto asesinato (el hecho fue cierto, pues la detención tuvo lugar) pero que, tras la resolución del caso, resulta absuelta y no se informa de esta decisión judicial. En el archivo digital permanecerán vinculados los datos de tal persona con la posible comisión de un delito de especial gravedad, sin referencia alguna a su absolución ${ }^{52}$. Un caso similar ha llegado recientemente al TS en relación con una noticia aparecida en El País en 2007 que hacía referencia a la imposición de sanciones por "caza furtiva» a un jefe forestal de Ourense $^{53}$. No obstante, en 2012 la persona en cuestión fue absuelta por el TSJ de Galicia ${ }^{54}$. En este caso, el TS ha señalado que, cuando la información

51 Sigue de este modo el TC lo que ya había señalado en su sentencia 129/2009, de 1 de junio, RTC/2009/129: «[...] el requisito de veracidad aparece referido al grado de diligencia observado para la comprobación de unos hechos con anterioridad a la publicación de aquéllos y no con que a posteriori se pruebe la realidad de los hechos» (FJ 4).

52 A un caso de este tipo se refiere la Resolución n. ${ }^{\circ}$ R/00741/2015 de la AEPD, si bien debe tenerse en cuenta que el derecho de cancelación se ejercitó únicamente frente al buscador Google y no frente a El Pais, que era el que contenía en su hemeroteca una noticia sobre un delito cometido en el año 1985 y del que fue absuelta la persona en cuestión por el propio TS en 1992.

53 STS, Sala Tercera, 12/2019, de 11 de enero, RJ/2019/8.

54 Ante tales hechos, el titular de los datos reclamó contra Google ante la AEPD, que determinó que el buscador debía desindexar la noticia. Frente a dicha resolución, el buscador interpuso recurso. No obstante, la AN compartió la solución de la Agencia señalando que "[...] no cabe negar el carácter sensible que para la vida privada el derecho de protección de datos personales del reclamante tiene la difusión a través de internet por el buscador de Google, de diversa información que le relaciona sin 
contenga datos inexactos que afecten en lo sustancial a la esencia de la noticia, debe prevalecer el derecho al olvido digital frente a la libertad de información, de modo que la persona titular de los datos puede reclamar «[...] cuando los resultados del motor de búsqueda ofrezcan datos sustancialmente erróneos o inexactos que supongan una desvalorización de la imagen reputacional que se revele injustificada por contradecir los pronunciamientos formulados en una resolución judicial firme» (FD 3). Conviene apuntar que en este caso la reclamación no se dirigió frente a la hemeroteca de los periódicos, que es el supuesto que nos ocupa, en cuyo caso entendemos que tendría que haberse incluido en la noticia una nota en la que se hiciera referencia a la absolución de la persona involucrada ${ }^{55}$.

En cambio, la Corte de Casación italiana sí tuvo la oportunidad de pronunciarse en relación con el conflicto con el webmaster en su sentencia de 22 de abril de 2012, n. ${ }^{0}$ 5525/2012 ${ }^{56}$. Il Corriere della Sera publicó el 22 de abril de 1993 una noticia relativa a la detención de un político local del Partido Socialista Italiano, acusado de un delito de corrupción, información que fue incorporada al archivo digital del diario. No obstante, tras el proceso judicial correspondiente, fue absuelto, pero ninguna referencia se hizo a este hecho por parte de la prensa. Tanto la agencia nacional de protección de datos como las distintas instancias previas a la casación hicieron prevalecer la libertad de expresión del diario y entendían que la noticia de la absolución podía encontrarse por otros medios. En cambio, la Corte de Casación consideró que la licitud del mantenimiento del nombre y apellidos del político en la noticia archivada sobre su detención se hacía depender de que la misma fuera

justificación suficiente con la comisión de una infracción como cazador furtivo, por lo que la ausencia de exactitud de la información facilitada en los enlaces ofrecidos por el buscador de Google y su carácter lesivo para la privacidad, consideración social y profesional del reclamante, determina que, en la ponderación de intereses que la Sala debe efectuar, y a la vista de los hechos expuestos, consideramos, compartiendo en este punto el criterio de la resolución combatida, que debe prevalecer en este supuesto, el derecho a la protección de datos del reclamante sobre el derecho a la libertad de expresión del buscador de Google [...]» (SAN de 18 de julio de 2017, JUR/2017/206454, FD 6).

55 En este sentido, aunque en relación con el buscador, el TS señaló que la información a la que remitía la lista de resultados "[...] no había sido actualizada por la sociedad responsable de la provisión de los servicios del motor de búsqueda a través de la remisión a enlaces que contuvieran la información referida a la decisión adoptada por la Sala de lo Contencioso-Administrativo del Tribunal Superior de Justicia de Galicia, que sirviera para completar los datos originariamente difundidos» (FD 3).

56 Disponible en: https://bit.ly/2ErVwgx. 
acompañada de una actualización de los hechos, pues, de lo contrario, no solo se vulneraría el derecho a la protección de datos de su titular, sino también el de la colectividad a conocer el desenlace del caso ${ }^{57}$.

Pues bien, coincidimos en este punto con el juzgador italiano, pero porque la noticia se refería a un personaje público. En efecto, la Corte no impuso al periódico la obligación de suprimir el nombre y apellidos o sustituirlos por sus iniciales porque la noticia se refería a un político, así como tampoco admitió la desindexación de la noticia por parte de los buscadores por la misma razón. No obstante, para evitar los efectos perjudiciales que el mantenimiento de dicha noticia podía suponer para su reputación, exigió una actualización de los datos, lo que se podía llevar a cabo por medio de una nota al final de la noticia o un enlace a informaciones posteriores, si las hubiera ${ }^{58}$. En cambio, consideramos que cuando el sujeto no tiene relevancia pública y la noticia antigua puede perjudicar el desarrollo del proyecto vital de la persona por contener información que finalmente resulta inexacta, no solo se debe desindexar la noticia de los buscadores, tal y como confirmó el TS en su sentencia de 11 de enero de $2019^{59}$, sino que también se debe proceder a la supresión de los datos personales. Y ello porque el perjuicio que podría provocar el mantenimiento de los datos en la reputación de la persona resultaría injustificadamente desproporcionado en relación con el derecho a recibir información veraz que corresponde a la sociedad, que en nada se vería afectado por no conocer el nombre y apellidos en estos supuestos ${ }^{60}$. ¿En qué contribuye a la formación de la opinión pública futura o a los fines históricos o de investigación la vinculación del nombre y apellidos de una persona sin relevancia pública con hechos respecto de los que no se pudo probar su participación? A nuestro juicio, en nada.

57 Sobre este asunto, véase Mantelero (2012: 843-849).

58 En el mismo sentido, Aberasturi Gorriño (2016: 10).

59 STS, Sala Tercera, 12/2019, de 11 de enero, RJ/2019/8, FD 3.

60 En cuanto a ello, la AEPD, en su Resolución n. ${ }^{\circ}$ R/02806/2012, impuso la cancelación de los datos a Google en relación con el enlace a una noticia de El País del año 2002 por un hecho del que después fue absuelta la persona involucrada. En cambio, en relación con la misma petición de cancelación de datos frente al periódico, la Agencia concluyó que el tratamiento estaba amparado por la libertad de información, de modo que no podía ser modificado el contenido de la noticia. Ahora bien, señaló que «[...] debiera ponderarse escrupulosamente la relevancia pública de la identidad de las personas afectadas por el hecho noticiable para, en el caso de que no aporte información adicional, evitar la identificación mediante la supresión del nombre e incluso, si fuera necesario, de las iniciales a cualquier referencia suplementaria de la que pueda deducirse la identificación [...]». 
Es en este concreto supuesto en el que, en nuestra opinión, debe quebrar el principio de integridad de las noticias de las hemerotecas.

De forma similar, el TEDH en los casos Wegrzynowski y Smolczewski c. Polonia y Times Newpapers Ltd ( $n^{\circ} 1$ y 2 ) c. Reino Unido consideró que era adecuado recoger notas de actualización o contextualización en relación con noticias contenidas en hemerotecas digitales sobre procedimientos judiciales respecto de los que posteriormente los reclamantes de protección de su derecho a la vida privada habían obtenido una sentencia a su favor. En el caso $M$. L. $y$ W. W. c. Alemania, dicho Tribunal no llevó a cabo un análisis en profundidad de este criterio, limitándose a considerar que los reportajes que se habían publicado en los distintos medios de prensa alemanes tenían naturaleza verídica y objetiva (párr. 98), relatando una decisión judicial, cuya veracidad y legalidad original no se había discutido en ningún momento (párr. 111).

\section{LA RELEVANCIA PÚBLICA DE LA INFORMACIÓN. EL TIEMPO COMO FACTOR DETERMINANTE PARA SU VALORACIÓN EN EL CONFLICTO CON EL DERECHO AL OLVIDO}

La relevancia pública de la información viene determinada, tradicionalmente, por dos criterios: el objeto de la información y el carácter público o privado de los sujetos a los que se refiere la noticia ${ }^{61}$. Es en este punto en el que el factor tiempo modula la forma en la que se ha venido valorando este criterio, tal y como afirma el propio TC en su sentencia de 4 de junio de 2018 (FJ 7).

En los casos resueltos por el TC y el TEDH, el objeto de las noticias lo constituían hechos con relevancia penal. En cuanto a ello, el tribunal europeo señaló que «[...] el público tiene en principio un interés en ser informado de los procedimientos de carácter penal y a poder informarse en este sentido [...]» (párr. 98)62. Por su parte, es sentada la doctrina del TC sobre la trascendencia pública de la información referida a hechos de carácter delictivo ${ }^{63}$. Ahora bien, en este punto la diferencia entre uno y otro caso es evidente. Mientras que en el supuesto que llegó al TEDH el delito era un asesinato, además, de un personaje público, en el caso resuelto por el TC la noticia venía

61 Así, SSTC 107/1988, de 8 de junio, RTC/1988/107, y 138/1996, de 16 septiembre, RTC/1996/138.

62 De igual modo, caso Axel Springer Ag c. Alemania, párrs. 80 y 96.

63 SSTC 178/1993, de 31 de mayo de 1993, ECLI:ES:TC:1993:178; 320/1994, de 28 de noviembre de 1994, ECLI:ES:TC:1994:320, y 185/2002, de 14 de octubre de 2002, ECLI:ES:TC:2002:185. 
referida a un delito menos grave de contrabando ${ }^{64}$. En consecuencia, tampoco fue igual el impacto que una y otra información tuvieron en la opinión pública, provocando mucha mayor conmoción en la sociedad el asesinato del afamado actor. Así, consideramos que cuanto mayor es la gravedad del hecho noticiable, mayor es el tiempo que la libertad de información debe prevalecer frente al derecho al olvido. En este sentido, el TS consideró que tal derecho debía ceder ante la libertad de información en un supuesto de una noticia de 2014 relativa a los conocidos como "crímenes de Calicanto", pues, pese al carácter privado de los sujetos que intervinieron en los mismos, los hechos tuvieron una gran repercusión social por la gravedad del delito cometido, entre otras razones ${ }^{65}$. De igual modo, la AEPD denegó la solicitud de cancelación de datos que se había ejercitado en 2015 frente a Google, La Voz de Galicia y La Opinión de la Coruña Media por considerar que una noticia de 2009 sobre la regencia de inmuebles de contactos en A Coruña por una mafia de explotación sexual era de tal relevancia pública que hacía prevalecer la libertad de información frente a la protección de datos ${ }^{66}$. Y lo mismo hizo en relación con un supuesto de una noticia de 2008 relativa a la detención de un médico chileno sin titulación convalidada en España que utilizaba la identidad de otro facultativo, convenció a una anciana de 94 años para un matrimonio de conveniencia y le estafó 20000 euros $^{67}$.

En cuanto al carácter público o particular de los sujetos involucrados en la noticia, en ambos casos las personas eran particulares sin trascendencia en la sociedad que, no obstante, la adquirieron por su participación en un hecho con relevancia pública, en concreto, en un delito. A este tipo de sujetos se refiere Mieres Mieres (2014: 29) como "personajes de relevancia pública accidental», en contraposición a los "personajes públicos», es decir, aquellos que ejercen el poder público, y a los "personajes de notoriedad pública», que son aquellas personas que por su profesión ocupan una posición que las expone al público, como actores ${ }^{68}$, o las relaciona con asuntos públicos, como

64 Cabe destacar que, tras la reforma del Código Penal de 2015, ya no está penado el delito en cuestión.

65 STS, Sala Primera, 426/2017, de 6 julio, RJ/2017/3194, FD 3.

66 Resolución n. ${ }^{\circ}$ R/02235/2015.

67 Resolución n. ${ }^{\circ}$ R/00646/2015. En este caso, el derecho de cancelación solo se había ejercitado frente a Google. Ahora bien, podemos sostener que, si no se apreció la solicitud en relación con el buscador, respecto del que el derecho al olvido tiene una virtualidad mayor, tampoco se concedería la petición de cancelación en el caso de que se hubiera dirigido la reclamación frente al periódico.

68 Así, caso Axel Springer Ag c. Alemania, párrs. 98 y 99. 
banqueros o empresarios ${ }^{69}$. Así, la libertad de información, incluida su función secundaria conseguida a través de los archivos digitales, debe prevalecer frente a la protección de datos cuando el sujeto involucrado en la noticia sea público $^{70}$. Como ejemplo, e independientemente del tiempo transcurrido, la infanta Cristina no podrá hacer valer su derecho al olvido en relación con las noticias en las que se informó a la población del denominado caso Nóos, ni frente a la prensa, ni frente a los buscadores, pues las mismas siempre contribuirán a la formación de la opinión pública de las futuras generaciones y al conocimiento de la historia de España ${ }^{71}$. Lo mismo cabría decir en relación con el uso del nombre y apellidos del político barcelonés que se vio involucrado en la red de tráfico de drogas a la que se refería la noticia que dio lugar al caso que llegó al TC ${ }^{72}$.

69 Dentro de esta categoría estaría, por ejemplo, el supuesto de un reputado arquitecto español de relevancia en Málaga que vio su nombre incorporado en una noticia de 2015 de la Cadena SER que hacía referencia a la condena de su pareja por fraude a Hacienda, supuesto que resolvió la APED por medio de la Resolución n. ${ }^{\circ}$ R/01021/2018. En este caso, la Cadena SER alegó que se trataba de un personaje público que desempeñaba un papel importante en la economía, argumento que fue acogido por la AEPD. En cualquier caso, como señala Cotino Hueso (2010: 310, nota 56): «La consideración de público de un personaje, obviamente es gradual y contextualizada [...]». Asimismo, podríamos entender incluidos en esta categoría a quienes Lazkano Brotóns (2015: 598) se refiere como sujetos con «dimensión institucional», como el representante de una comunidad religiosa.

70 Este es el único criterio que aporta el TJUE en el caso Google para ponderar el derecho al olvido con las libertades informativas (párr. 99).

71 Sobre este asunto concreto, véase Berrocal Lanzarot (2017: 292-293). En cuanto a ello, y, sobre la base del proceso cerebral relativo al olvido, afirman Korenhof et al. (2015: 176) que son tres los elementos que intervienen en el mismo: el paso del tiempo, la importancia de la información y la regularidad con la que la misma es utilizada. De este modo, cuanta más importancia tenga la información, será más empleada y, por tanto, tardará más tiempo en olvidarse. De hecho, estos autores llegan a afirmar que en el caso de personas que desempeñan una función pública, sus datos personales no pueden ser objeto de supresión nunca cuando los mismos están relacionados con aquella (Korenhof et al., 2015: 188).

72 Ahora bien, no todo ejercicio de la función pública tiene la misma relevancia o importancia para la sociedad. Así, el TS consideró que, pese a que el jefe forestal de Ourense era un funcionario público, «[...] sus actuaciones carecían de particular notoriedad pues no ha quedado acreditado en autos que se trate de un personaje público o que desempeñase, indiciariamente, un papel destacado en la vida pública de esa Comunidad Autónoma, lo que diluye en gran medida el interés público de la información difundida a través de internet [...]» (STS, Sala Tercera, 12/2019, de 11 de enero, 
La duda surge, fundamentalmente, en relación con las personas que adquieren relevancia pública por su «tropiezo» con la justicia. En estos casos, entendemos que, si el delito no es de especial gravedad, igual que vino tal trascendencia, debe irse por el paso del tiempo ${ }^{73}$. Este sería el supuesto del caso resuelto por el TC. En cambio, el asesinato del afamado actor que se relató por la prensa alemana tuvo un impacto en la sociedad que hizo a los hermanastros adquirir una relevancia pública mayor. Es cierto, como señala el TEDH, que con el paso del tiempo los solicitantes de protección fueron perdiendo notoriedad. No obstante, entendemos que la gravedad de tales hechos hace que el tiempo necesario para poder exigir que se olviden sea mayor que en el caso español.

En este punto, conviene poner de relieve que, si bien el transcurso del tiempo tiende a reducir el grado de relevancia pública de la información, las propias actuaciones del sujeto pueden hacer renacer el interés por la misma ${ }^{74}$. Así, la conducta previa de la persona que quiere ver salvaguardado su derecho a la protección de datos es especialmente tenida en cuenta por el TEDH a la hora de resolver el caso M. L. y W. W. c. Alemania. Recuérdese que los hermanastros habían ejercitado todos los recursos existentes para revisar la sentencia condenatoria, así como que uno de ellos se había puesto en contacto con la prensa con el objeto de informar acerca de los avatares del procedimiento. De este modo, los particulares, que con el tiempo habían ido perdiendo notoriedad, volvieron a saltar a la palestra por su propia voluntad, razón por la que no podían pretender que fueran olvidados (párrs. 107-109). En el ámbito español, también encontramos una situación similar en relación con el

RJ/2019/8, FD 3). Por ello, y por la inexactitud de los hechos contenidos en los enlaces tal y como se señaló previamente, el citado tribunal hizo prevalecer el derecho al olvido digital frente a la libertad de información alegada por Google.

73 En este sentido, señala Rallo (2014: 26-27) que «[...] el derecho a saber y a estar informados alcanza sin matices todo asunto de interés general pero no a cualquier dato personal que voluntariamente o no haya sido hecho público por un particular en el marco de sus relaciones personales». En relación con ello, la Sala Tercera del TS consideró que el paso del tiempo hacía prevalecer el derecho a la protección de datos frente a la libertad de información invocada por el buscador Google en el supuesto de una noticia aparecida en El País y en el $A B C$ en el año 1992 sobre la condena a un ginecólogo por una falta de imprudencia en relación con el fallecimiento de una persona en la que había dejado compresas en una operación (SAN de 13 de julio de 2017, JUR/2017/208178, FD 5). No obstante, la reclamación de protección de datos no se dirigió frente a los medios de prensa, razón por la que la noticia completa seguía disponible en la hemeroteca.

74 En cuanto a ello, Cotino Hueso (2010: 311, nota 57) señala que el propio interesado en la protección de sus datos puede rebajar la protección de sus derechos con su actitud. 
conocido señor Mario Costeja. Tras la resolución del caso Google, el que ha sido considerado como el promotor del derecho al olvido volvió a dirigirse frente al buscador con la petición de que desindexara una noticia sobre él del año 2014. En este caso, Google alegó que se trataba de un personaje público respecto del que su nombre y apellidos aparecerían siempre unidos a una sentencia que ha sido de especial interés, por lo que no podía pretender que el buscador no recuperara noticias suyas a través de tales datos, argumento que fue acogido por la AEPD, que destacó que el propio Mario Costeja se había expuesto al público en varias ocasiones, además de que había transcurrido muy poco tiempo desde la publicación de la noticia ${ }^{75}$.

Ahora bien, ¿qué tiempo es el que debe transcurrir para considerar que la noticia ha perdido la relevancia pública que hace prevalecer la libertad de información sobre la protección de datos de carácter personal? La respuesta no puede ser otra que la siguiente: depende de las circunstancias del caso concreto. Por ello, aunque existen técnicas que permiten borrar los datos personales de forma automática tras el paso del período de un tiempo establecido, como la herramienta Vanish, las mismas no valoran las particularidades de cada circunstancia, de modo que tratarían de un modo igual casos diferentes que requerirían un estudio concreto de ponderación de derechos (Mieres Mieres, 2014: 8 y Jiménez-Castellanos Ballesteros, 2018: 231-232).

Con carácter general, en la valoración del criterio de la relevancia pública de la información, el factor tiempo actúa de manera inversamente proporcional, tal y como señala, entre otros, Seligrat González (2015: 5). Así, cuanto menor es el tiempo transcurrido entre la publicación del dato personal y el hecho noticiable, mayor será la protección del derecho del profesional de la información frente al derecho al olvido, y a la inversa, cuanto mayor sea el tiempo transcurrido entre tal publicación y el hecho del que trajo causa, menor será el peso que deba darse a la libertad de información en la balanza, en favor del derecho al olvido. El tiempo, por tanto, debilita la prevalencia que tradicionalmente se ha venido atribuyendo a las libertades informativas sobre otros derechos de la personalidad. Efectivamente, el equilibrio entre los derechos fundamentales al honor y la intimidad y la protección de datos como

75 Resolución n.o R/02179/2015. En concreto, Google señaló: «El hecho de que el Sr. [...] haya decidido de forma deliberada contribuir activamente al debate público, mediante su participación constante en entrevistas en medios de comunicación escrita, radiofónica y audiovisual, determina que el interés legítimo de la sociedad en acceder a informaciones y opiniones sobre él, también a través de motores de búsqueda al realizar una búsqueda a partir de su nombre, debe prevalecer sobre su derecho a la protección de datos. El Sr. [...] no puede ahora pretender actuar en contra de sus propios actos». 
instrumental de aquellos y las libertades informativas no es estático, sino que la balanza se va inclinando de un lado a otro en función de distintos elementos. El derecho al olvido nace cuando el determinante para que la misma se incline del lado de los derechos de la personalidad es el transcurso del tiempo ${ }^{76}$.

Ahora bien, ese criterio general encuentra excepciones concretas, como cuando la persona o el hecho al que se refiere la información tiene una especial relevancia pública, pues en ese caso siempre existirá un interés histórico en su conocimiento que favorece la formación libre de la opinión pública futura, o cuando es la propia persona la que dota de nuevo a la información de trascendencia pública con su actuación.

En cualquier caso, el tiempo que ha de transcurrir entre los hechos noticiables y la apreciación del derecho al olvido ha de ser considerable, pues se requiere que la noticia resulte obsoleta como consecuencia de tal circunstancia. Es en ese caso en el que el tratamiento de los datos deviene inadecuado o excesivo en relación con la finalidad para que la fueron recogidos y, por tanto, resulta contrario al principio de calidad ${ }^{77}$. En relación con ello, la AEPD ha señalado en varias ocasiones que el derecho al olvido no abarca la eliminación de información todavía reciente ${ }^{78}$. En consecuencia, no ha aceptado solicitudes de cancelación de datos en relación con noticias aparecidas incluso cuatro años antes de la reclamación ante la Agencia ${ }^{79}$. En definitiva, y como señala Rallo (2014: 127), el transcurso del tiempo debe venir asociado a otras circunstancias para que pueda apreciarse el derecho al olvido.

\section{MEDIDAS PARA EL RESTABLECIMIENTO DEL DERECHO AL OLVIDO. EL GRADO DE DIFUSIÓN DE LA INFORMACIÓN COMO CRITERIO PARA SU DETERMINACIÓN}

El TEDH concluyó que el Estado alemán había cumplido con sus obligaciones derivadas del art. $8 \mathrm{CEDH}$, pues la libertad de información debía prevalecer, especialmente por la relevancia pública de los hechos noticiados y

76 En este sentido, véase Korenhof et al. (2015: 176).

77 En este sentido, el art. 5.1 c) RGPD establece: «Los datos personales serán: [...] adecuados, pertinentes y limitados a lo necesario en relación con los fines para los que son tratados ("minimización de datos")». Al mismo principio se refería el art. 4.1 LOPD ya derogado. En cambio, resulta llamativo que el único principio relativo a la calidad de los datos previsto en la nueva LOPDGDD sea el relativo a la exactitud de los datos, sin hacer referencia alguna al de la adecuación. No obstante, siempre será posible la alegación directa del precepto del RGPD.

78 Así lo señala, entre otras, en las resoluciones n. ${ }^{\circ} \mathrm{R} / 03366 / 2017$ y R/01021/2018.

79 Resolución n. ${ }^{\circ}$ R/01171/2016. 
por el escaso grado de difusión de las noticias. En efecto, las informaciones completas se habían incorporado en la sección de informaciones menos recientes e, incluso, alguno de los medios había sometido su acceso completo al pago de una suscripción. Aunque ciertamente la conservación de las noticias en la red puede provocar una accesibilidad permanente a las mismas, el TEDH tuvo en cuenta que los hermanastros no se dirigieron en ningún momento a los buscadores generales de internet para reducir la visibilidad de las mismas (párr. 114).

Esta última consideración del Tribunal pone de relieve el carácter trascendental que ocupa el grado de difusión de la noticia a la hora de establecer medidas para restablecer al particular en su derecho a la protección de datos. En efecto, la persona que aparecía en la noticia en papel de un diario de los años ochenta que solo podía consultarse en la Biblioteca Nacional de España no se planteaba en ningún momento solicitar que sus datos personales fueran suprimidos, simplemente por el hecho de que la información en cuestión no era objeto de difusión, era desconocida, «olvidada». La digitalización de las noticias, en cambio, multiplica exponencialmente las posibilidades de acceso a las mismas ${ }^{80}$. Por tanto, en los supuestos en los que la información fue veraz, pero el transcurso del tiempo haya provocado que la misma devenga obsoleta, esto es, carente de relevancia pública actual, la medida que deba adoptarse para restablecer al particular en su derecho al olvido dependerá del grado de difusión que se le haya dado a la misma ${ }^{81}$. Este sería el supuesto, precisamente, del caso resuelto por el TC en su sentencia de 4 de junio de 2018.

En cuanto a ello, cabe destacar que todas las hemerotecas digitales cuentan con un buscador interno, esto es, una herramienta informática que indexa (o incluye en su índice) determinadas palabras contenidas en las noticias del archivo digital de manera que, si las mismas son introducidas como criterio de búsqueda, aparecerán tales informaciones como resultado. De esta forma, se facilita considerablemente la búsqueda de la información. Su funcionamiento coincide con el de cualquier otro buscador general, como Google o Yahoo ${ }^{82}$, si bien existen dos elementos que diferencian a los buscadores internos de los

80 En este sentido, el TEDH ya puso de manifiesto en el caso Equipo Editorial de Pravoye Delo y Shtekel c. Ucrania que la capacidad de transmisión de información de la prensa escrita y la que se contiene en internet es radicalmente distinta, razón por la que la respuesta que debe darse al tratamiento de datos en internet que puede afectar a la vida privada de las personas debe ser distinta de aquella que resuelve el conflicto con la prensa en papel (STEDH de 5 de mayo de 2011, JUR 2011/140886, párr. 63).

81 En el mismo sentido, Jiménez-Castellanos Ballesteros (2018: 309).

82 Detallan el funcionamiento de los buscadores el AG en el caso Google en sus conclusiones de 25 de junio de 2013, C-131/012, párr. 34, y Aparicio Salom (2018: 395-396). 
externos (Article 29 Data Protection Working Party, 2014: párr. 18). Por un lado, mientras que los buscadores externos o generales indexan información de todas las páginas web de la red, los internos de las hemerotecas únicamente recuperan datos de los contenidos alojados en las mismas. En consecuencia, y, por otro lado, la búsqueda por nombre y apellidos de una persona en el buscador interno solo dará como resultado la información sobre tal persona que haya sido indexada y que se contenga en la propia hemeroteca, pero ninguna otra. En cambio, los buscadores generales, al rastrear todas las páginas de la web, ofrecen perfiles más completos de la persona afectada por la combinación de distintas fuentes de información, con fotos, vídeos y comentarios en redes sociales, por ejemplo, lo que puede afectar en mayor medida a su reputación ${ }^{83}$. Por ejemplo, cada vez es más frecuente que el personal de recursos humanos realice búsquedas por el nombre y apellidos de los aspirantes a un puesto de trabajo para conocer, a través de la lista de resultados, sus preferencias personales, intereses, fiabilidad, posibles desencuentros con la justicia, etc. En estos casos, le será de gran utilidad el buscador general o externo, pero no tanto el propio de una hemeroteca digital.

Precisamente son estas diferencias entre uno y otro buscador las que llevan al TS en su sentencia de 15 de octubre de 2015 a revocar parcialmente la de apelación. En relación con los buscadores generales o externos, el TS mantiene la imposición de la medida establecida en la SAP Barcelona de 11 de octubre de 2013 consistente en desindexar el nombre y apellidos de las hermanas, por el mayor riesgo de creación de perfiles que los mismos entrañan. En cambio, dado el menor alcance y efecto de la búsqueda a partir del nombre y apellidos de una persona en el buscador interno y la contribución de este instrumento para la difusión de la información de la hemeroteca entre los internautas más activos, el Tribunal llega a la conclusión de que no es proporcionado exigir la desindexación a El País respecto a su buscador interno

83 Así lo pone de relieve el Comité de Ministros del Consejo de Europa (2012) cuando señala: «By combining different kinds of information on an individual, search engines create an image of a person that does not necessarily correspond to reality or to the image that a person would want to give of her- or himself. The combination of search results creates a much higher risk for that person than if all the data related to her on the Internet remained separate». Ahora bien, resulta necesario precisar en este punto que el buscador no lleva a cabo por sí mismo un tratamiento consistente en la elaboración de perfiles tal y como se define en el art. 4.4) RGPD, sino que, al recoger entre sus resultados información procedente de toda la web y presentarla de forma ordenada, posibilita y facilita al usuario del buscador la creación de los mismos. 
$\left(\right.$ FD 7 ${ }^{84}$. El Tribunal sigue así la recomendación llevada a cabo por el Article 29 Data Protection Working Party (2014: párr. 18), que señala que, como regla general, el derecho a la desindexación frente a los buscadores no debe ser aplicable a los buscadores de las webs de la prensa ${ }^{85}$.

Aunque el TS no aclara lo que entiende por «audiencia más activa en la búsqueda de información», a la que pretende proteger admitiendo la indexación de la noticia en el buscador interno, entendemos que se refiere a aquel internauta que no se conforma con los resultados de la búsqueda general, que es lo que hace el usuario de la red habitualmente, sino que se preocupa por acceder a la página web de la hemeroteca del medio de prensa en cuestión. Por esta razón, el Tribunal equipara la búsqueda en el buscador interno del archivo digital con la que hacía el investigador que acudía a la hemeroteca física. No obstante, no han sido pocas las críticas que, con razón, se han hecho a esta afirmación del Tribunal por parte de la doctrina (Aberasturi Gorriño, 2016: 17; Di Pizzo Chiacchio, 2018: 186; Pizarro Moreno, 2016: 339-342). El Tribunal no repara en que los criterios de búsqueda empleados en la red en este caso son los nombres y apellidos de personas que carecen de relevancia pública, términos que con total seguridad no se encontrarán en los índices de búsqueda de las hemerotecas físicas. Así, la búsqueda efectuada en el buscador interno del archivo digital genera un riesgo de vulneración de la protección de los datos personales que no existía en los archivos en papel. En ello estriba la diferencia entre la hemeroteca física y la virtual, y de ahí surge la necesidad de dar una respuesta adecuada a las particularidades que plantea el segundo supuesto. Además, la desindexación por parte del buscador interno no impide el acceso a la noticia completa, incluidos los nombres y apellidos de las hermanas, por medio de este buscador e incluso de los externos, pero a partir de otros criterios de búsqueda. De esta forma, consideramos que se consigue la denominada "oscuridad práctica ${ }^{86}{ }^{\text {» }}$ a la que se refiere el propio TS, pero de forma más equilibrada con el derecho del particular.

84 De igual modo, la SAN 100/2015, de 24 de febrero, RJCA/2015/468, en el caso de la rotura de la mano de la Cibeles, desestimó el recurso del particular por considerar que, desindexado su nombre y apellidos de los buscadores generales, no podía exigirse la misma medida en relación con los buscadores internos (FJ 1). Lo mismo resuelve la Sala Primera del TS en la sentencia 426/2017, de 6 julio, RJ/2017/3194, en el caso de los «crímenes de Calicanto" (FD 5).

85 "Therefore, as a rule the right to de-listing should not apply to search engines with a restricted field of action, particularly in the case of search tools of websites of newspapers».

86 En cuanto al oscurecimiento, considera Pazos Castro (2016: 25) que con esa medida se corre el riesgo de que se tenga más información de quien realizó conductas reprochables, pero de escasa importancia, frente a quien realizó actos más graves. 
Por ello, coincidimos plenamente con la solución a la que llega el TC al respecto, para quien la desindexación de los nombres y apellidos de las recurrentes tanto en buscadores externos como en el interno de la hemeroteca resulta una «medida limitativa de la libertad de información idónea, necesaria y proporcionada" para restablecerlas en sus derechos $(\mathrm{FJ} 8)^{87}$. Como señala el Tribunal, la «audiencia más activa en la búsqueda de información» a la que se refiere el TS puede acceder a la noticia por criterios geográficos, temporales o temáticos, que son los que vinculan la noticia antigua con la formación de la opinión pública. En cambio, la búsqueda de información a partir del nombre y apellidos de personas que no tienen relevancia para la sociedad únicamente pretende «satisfacer la curiosidad individual y focalizada» (FJ 8) ${ }^{88}$. Se evita así el cotilleo al que se refiere el TS y que no está amparado por la libertad de información ${ }^{89}$. Reducida de este modo la difusión de la información de forma

87 De la misma opinión se muestra Seligrat González (2015: 9-10), quien ya aporta esta solución al hilo del comentario de la sentencia del TS, la cual critica en este punto.

En cuanto a ello, cabe destacar que el derecho al olvido se ha considerado aplicable en relación con la búsqueda a partir del nombre y apellido, pero no a partir de otros datos personales como las fotografías. Así, el TS entendió en el caso relativo a la noticia de los "crímenes de Calicanto" que el recurrente no podía alegar su derecho al olvido en relación con dicha información, pues en la misma se habían omitido su nombre y apellidos, y, aunque aparecía una foto suya y esta pueda considerarse como un dato de carácter personal, no es posible encontrar la noticia en un buscador a partir de dicha imagen (STS, Sala Primera, 426/2017, de 6 julio, RJ/2017/3194, FD 5). En este sentido, el TS ha definido recientemente el derecho al olvido digital como la facultad de solicitar que se «[...] cancele, suprima o prohíba la indexación de aquellos datos de la lista de resultados proporcionada por el motor de búsqueda obtenidos a partir de su nombre [...]» (STS, Sala Tercera, 12/2019, de 11 de enero, RJ/2019/8, FD 3). Asimismo, la AN consideró en un supuesto de solicitud de desindexación contra Google que cuando se ejercita el derecho de oposición, el interesado "[...] ha de indicar ante el responsable del tratamiento, o ante la Agencia Española de Protección de Datos, que la búsqueda se ha realizado a partir de su nombre como persona física [...]» (SAN de 29 de diciembre, JUR\2015 26978, FD 9).

En cuanto a ello, la STC 20/1992, de 14 de febrero, RTC/1992/20, FJ 3, seguida, entre otras, por la STC 185/2002, de 14 octubre, RTC/2002/185, FJ 4, ya vino a señalar que "[...] la relevancia comunitaria [de la información], y no la simple satisfacción de la curiosidad ajena, con frecuencia mal orientada e indebidamente fomentada, es lo único que puede justificar la exigencia de que se asuman aquellas perturbaciones o molestias ocasionadas por la difusión de una determinada noticia [...]». De igual modo, el TC destacó que no cabe identificar el «interés público» con el «interés del público", en su sentencia 7/2014, de 27 enero de 2014, RTC/2014/7, FJ 4. Así, el «interés público» digno de protección constitucional es el que deriva de aquella infor- 
considerable, la supresión de los nombres y apellidos o su sustitución por las iniciales supondría una medida innecesaria para el Tribunal por dos razones ${ }^{90}$. Por un lado, porque las recurrentes habrían visto tutelados sus derechos con la oscuridad práctica conseguida a través de la desindexación de los buscadores externos e interno de la hemeroteca. Y, por otro, porque la imposición de dicha medida traería consigo una injerencia desproporcionada en la libertad de información, debiendo procurarse la integridad de los contenidos que fueron noticiables y que se contienen en la hemeroteca de la prensa ${ }^{91}$. Compartimos la valoración del Tribunal y añadimos dos argumentos más a favor de la conservación de los nombres y apellidos de personajes con relevancia pública accidental en una noticia antigua. En primer lugar, aunque la persona que cometió el hecho en el pasado sea un particular en el presente, nada impide que pueda llegar a ser una persona con relevancia pública en el futuro, como,

mación con trascendencia para la comunidad, a diferencia del «interés del público» que se desprende de la que pretende simplemente satisfacer la curiosidad de ciertos sectores. En este sentido, el TEDH consideró en el caso Von Hannover c. Alemania que la publicación de varias fotografías de la hija mayor del príncipe Rainiero III de Mónaco en distintas revistas alemanas tenía como único fin «[...] satisfacer la curiosidad de cierto público sobre los detalles de la vida privada de la demandante [...]», razón por la que «[...] no puede considerarse que contribuya a ningún debate de interés general para la sociedad, pese a la notoriedad de la demandante [...]» (párr. 65). De forma similar, en un supuesto en el que un particular solicitaba al buscador Google la desindexación de su nombre y apellidos en relación con una resolución sancionadora publicada en el Boletín Oficial del País Vasco, la AN vino a señalar que «[...] debe ponerse de manifiesto que la libertad de información de los editores, en principio, se encuentra satisfecha por su subsistencia en la fuente, es decir, en el sitio web donde se publica la información por el editor. Cuestión distinta es si cabe apreciar la existencia de un interés del público en encontrar la información, en relación con la cual se ejercita el derecho de oposición, en una búsqueda que verse sobre el nombre del afectado que deba prevalecer sobre el derecho a la protección de datos personales de este» (SAN de 29 de diciembre de 2014, JUR/2015/26978, FD 8). Por ello, la citada Audiencia desestimó el recurso interpuesto por Google y confirmó la adopción de la medida consistente en la desindexación, de manera que «[...] si bien la citada información no aparecerá conectada con el interesado en una búsqueda realizada por su nombre en el citado buscador, permanece en la fuente o web master no habiendo desaparecido de las páginas oficiales» (FD 9).

91 En este sentido, Aberasturi Gorriño (2016: 7) considera que: «La supresión de la información de las páginas web carecería de sentido si se tiene en cuenta que la publicación estuvo justificada en su día y amparada en los citados principios de veracidad y relevancia pública». En contra, López Calvo (2018: 3-4) sostiene que mantener el nombre y los apellidos en la noticia «diluye» el derecho al olvido. 
por ejemplo, cuando decide iniciar la carrera política. En estos casos, a la población le interesará conocer todos los hechos relacionados con su vida, especialmente, los que pudieran haber tenido carácter noticiable, pues ello le permitirá formarse una opinión libre y completa acerca de una persona que puede ostentar un cargo público. En segundo lugar, y desde una perspectiva económica, la imposición de una obligación a la prensa de suprimir los datos de todos los particulares que alguna vez fueron objeto de una noticia podría conllevar unos gastos tales que se desincentivaría a los medios de comunicación a mantener sus hemerotecas digitales ${ }^{92}$.

A diferencia del supuesto resuelto por el TC, en el que la hemeroteca solo permite acceder a información pasada a través de la fecha o del buscador interno, otras incorporan en su página de inicio noticias del pasado, como las de los diarios $A B C$ y La Vanguardia, sin que sea necesario buscarlas de forma específica. En estos casos, el archivo digital realiza un nuevo tratamiento ${ }^{93}$, para cuya legitimidad es necesario que la noticia guarde relación con la situación actual. A nuestro juicio, retomar informaciones pasadas y darles una nueva difusión sin necesidad de que tengan que ser buscadas una vez se accede a la hemeroteca digital del periódico requiere que exista una conexión entre aquel hecho y uno actual para que este tratamiento de datos sea legítimo. Por ejemplo, porque se trata del mismo sujeto y han aparecido nuevos datos sobre el mismo o porque se pretende hacer una comparación entre el pasado y el presente en el ámbito político. La razón que nos lleva a esta conclusión parte del siguiente hecho. El internauta que accede a la hemeroteca de un medio de prensa normalmente lo hace con la intención de buscar una información en particular, sobre un hecho o persona determinados. No obstante, si se le presentan en la página de inicio otras informaciones, es muy probable que las ojee y que llegue a abrir alguna de las noticias así ofrecidas. Es decir, el grado de difusión de las informaciones pasadas directamente presentadas al internauta en la página de inicio de la hemeroteca es mayor que el de aquellas respecto de las que se precisa una búsqueda. Así, carecería de relevancia alguna que la noticia que dio lugar a la STC de 4 de junio de 2018 fuera presentada en la cabecera de la hemeroteca digital de El País, pues la información no

92 A dicho riesgo hizo referencia, precisamente, el Tribunal Federal alemán en relación con el caso M. L. y W. W. c. Alemania, tal y como se narró previamente.

93 Así, la inclusión de la noticia en el archivo digital equivaldría a su «registro», "organización», «estructuración» y «conservación», mientras que la nueva difusión en la página de inicio de la hemeroteca se correspondería con un acto de "comunicación por transmisión» o "difusión», atendiendo a los términos con los que el art. 4.2) RGPD define el «tratamiento». 
tiene en la actualidad ni tuvo tampoco en su momento especial trascendencia pública (FJ 8), a excepción de la participación en la red de tráfico de drogas del hermano de un político barcelonés. En este caso, por tanto, entendemos que deberían sustituirse los nombres y apellidos de las personas sin relevancia pública por sus iniciales. En cambio, en el asunto M. L. y W. W. c. Alemania estaría justificado un tratamiento como el señalado en la fecha en que se cumplieran años del asesinato del afamado actor, por ejemplo, pues, tal y como señala el propio tribunal, la noticia tuvo una gran repercusión social y venía referida a un personaje de especial relevancia pública.

Ahora bien, en estos supuestos, la mayor difusión a la que se ven expuestos los datos de las personas unidos a hechos que pueden afectar a su reputación requiere una actuación adicional por parte del webmaster para que el perjuicio que pueda ocasionarse a sus titulares esté justificado y suponga un sacrificio proporcionado en favor de la libertad de información. A nuestro juicio, y aplicando el mayor deber de diligencia en relación con la exactitud de los hechos cuando se trata de noticias del pasado que exige el TEDH en

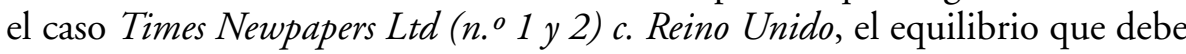
existir entre el ejercicio del derecho a la información cuando cumple con su segunda función y el derecho a la protección de datos personales requiere que se adopte una medida de actualización cuando la información es presentada directamente en la página de inicio de la hemeroteca. Ello se puede llevar a cabo mediante la inclusión de una nota en la que se informe acerca de los nuevos datos que hayan podido conocerse y no se contuvieran en la noticia original o bien mediante el enlace a noticias posteriores en las que se hiciera seguimiento del suceso en cuestión. En este sentido, debe tenerse en cuenta que la aparición directa de estas noticias no solo tiene por objeto facilitar el acceso a la información a los internautas, sino ofrecer un servicio adicional que se traduzca en mayores visitas a la hemeroteca en cuestión. En consecuencia, la mayor exposición de los datos de las personas por la prensa en estos casos debe ir acompañada de un mayor grado de responsabilidad del webmaster en relación con dicho tratamiento ${ }^{94}$. Ahora bien, consideramos que esta medida solo es aplicable a este supuesto concreto y al caso en el que la noticia se refiera a un hecho delictivo relacionado con un personaje público, del que después es absuelto, tal y como se señaló previamente. Con carácter general, debe preservarse la integridad de las hemerotecas, pues el establecimiento de un deber

94 En relación con las mayores visitas a una página web, señala con acierto Brotons Molina (2013: 120) que, si una empresa fomenta el tráfico en la misma, con el consecuente beneficio económico que ello supone, se le debe exigir un cierto grado de responsabilidad por la mayor exposición de los datos personales. 
general de contextualización desincentivaría a la prensa en cuanto al mantenimiento de sus archivos digitales, por los costes humanos y temporales que ello conllevaría. Ello supondría el fin del cumplimiento de la segunda función de la libertad de información.

\section{CONCLUSIONES Y COMPARATIVA CON EL ALCANCE DEL DERECHO AL OLVIDO FRENTE A LAS HEMEROTECAS SEGÚN SU RECIENTE RECONOCIMIENTO LEGAL}

La digitalización de las hemerotecas de la prensa ha provocado que noticias ya olvidadas sean traídas al presente, pudiendo afectar a la reputación de las personas. De ahí surge el conflicto entre la libertad de información de los profesionales de la información y el derecho a la protección de datos personales.

La prensa, entendida como el conjunto de los profesionales que se dedican a la difusión de información veraz y noticiable, esto es, de trascendencia pública, por cualquier medio, lleva a cabo una doble función. La primaria consiste en contribuir a la formación de una opinión pública libre, como pilar de toda sociedad democrática y de derecho. La secundaria permite a las generaciones futuras conocer el pasado mediante la educación y la investigación histórica a través de las hemerotecas. El contenido, por tanto, de los archivos de la prensa se encuentra amparado por la libertad de información, si bien con una protección menor que cuando los profesionales del periodismo cumplen con su función primaria.

Estando amparado el tratamiento de datos personales por las hemerotecas digitales por la libertad de información, el transcurso del tiempo y la expansión de la difusión de las noticias antiguas a través de internet generan un riesgo en los derechos al honor y la intimidad de la persona que pueden verse reducidos por medio del ejercicio del derecho al olvido. Su alcance y efectos dependerán del supuesto concreto de que se trate. Como regla general, debe preservarse la integridad del contenido de los archivos digitales que sea el resultado del ejercicio de la libertad de información, de modo que se mantengan todos los datos contenidos en las noticias del pasado. En estos casos, el derecho al olvido de las personas sin trascendencia pública se corresponde con la adopción de medidas tendentes a conseguir la "oscuridad práctica» de la información, es decir, con la obligación de la página web de la hemeroteca de desindexar los datos de carácter personal tanto del buscador interno del archivo, como de los externos o generales, en línea con la decisión adoptada por el TC en su sentencia de 4 de junio de 2018. De este modo, es posible acceder a la información completa de la hemeroteca, pero a través de criterios distintos 
de los de los datos personales de una persona sin trascendencia pública, lo que reduce considerablemente la posibilidad de que la persona que intente satisfacer su interés particular por otra pueda llegar a encontrar la información en cuestión. Ello debe ser así, a nuestro juicio, a excepción de un supuesto: cuando se trata de hechos relativos a un delito cometido por una persona sin relevancia pública respecto del que después es absuelto. En este caso, la medida proporcionada para ponderar los derechos a la libertad de información y a la protección de datos será la supresión del nombre y apellidos o, al menos, su sustitución por sus iniciales, por el mayor deber de diligencia que cabe exigir a la prensa en relación con la exactitud de los hechos cuando ejercita la libertad de información para cumplir con su segunda función. Este sería el único supuesto en el que la integridad de las noticias del pasado se vería quebrantada. Por último, cuando esta misma situación se refiera a un personaje de carácter público, así como cuando la página inicial de la hemeroteca ofrezca al usuario noticias del pasado, la concesión que tendrá que llevar a cabo la libertad de información en favor de la protección de los datos consistirá en la contextualización de los mismos, mediante notas de actualización de la información o a través de enlaces a posteriores noticias sobre el asunto.

Aunque consideramos que el alcance del derecho al olvido debería ser el que se ha señalado hasta el momento, lo cierto es que su regulación por parte del RGPD se aleja considerablemente de lo señalado. En cambio, la reciente LOPDGDD contempla en su articulado dos preceptos próximos a la postura sostenida en este trabajo.

El propio título del art. 17 RGPD identifica el derecho al olvido con el derecho de supresión. En cambio, a nuestro juicio, el derecho al olvido se corresponde, en la mayoría de los casos, con un derecho a la desindexación ${ }^{95}$, pero no con la eliminación de los datos de la fuente original cuando esta es una hemeroteca de la prensa, dada la importancia que a estos archivos le ha atribuido el propio TEDH. Algunos autores han visto en el entrecomillado del derecho al olvido en el título que el primer apartado del precepto recoge el derecho de supresión y es el segundo el que regula específicamente el del olvido $^{96}$. En cualquier caso, el apartado tercero del mismo precepto establece en su literal a) que el derecho de supresión regulado en los apartados anteriores no será de aplicación al tratamiento que sea necesario para ejercer el derecho a la libertad de expresión e información. Si, como hemos sostenido hasta el momento, las noticias de las hemerotecas digitales están amparadas por la

95 En este sentido, Di Pizzo (2018: 272) alerta de que el derecho al olvido del art. 17 RGPD es más amplio que el configurado por el TJUE en el caso Google.

96 En este sentido, véase Jiménez-Castellanos Ballesteros (2018: 230). 
libertad de información, ello supondría que el derecho al olvido no tendría efecto frente a los archivos digitales de la prensa, lo que sin duda alguna carece de toda lógica habida cuenta de que tal derecho tuvo su origen jurisprudencial en una noticia antigua. Por otro lado, el art. 85 del mismo reglamento impone a los Estados miembros la obligación de conciliar el derecho a la protección de datos con la libertad de expresión e información (apdo. 1), para lo que deberán establecer exenciones o excepciones legales, entre otros aspectos, a los derechos del interesado (apdo. segundo), como lo es precisamente el derecho al olvido ${ }^{97}$. En este contexto, nos preguntamos, ¿̇tiene algún sentido que el art. 17.3 RGPD declare inaplicable el derecho de supresión o al olvido en el caso de que se ejercite la libertad de información y, al mismo tiempo, el art. 85.2 establezca que los Estados miembros deben crear excepciones a tal derecho cuando el tratamiento de datos se haga para fines periodísticos? Si el derecho en cuestión ya es inaplicable en virtud del primer precepto, el segundo carece de toda virtualidad. Asimismo, resulta especialmente criticable que el art. 17 RGPD no haga mención alguna al factor clave que hizo nacer el derecho al olvido: el paso del tiempo.

En cuanto a la LOPDGDD, su aprobación tuvo como finalidad fundamental adaptar la anterior LOPD al RGPD, tal y como señala el apdo. III de su preámbulo. Pues bien, en un novedoso título X dedicado a la "Garantía de los derechos digitales», se contemplan el derecho a la actualización de informaciones en medios de comunicación digitales (art. 86) y el derecho al olvido en búsquedas de internet (art. 93) ${ }^{98}$. En virtud del art. 86 LOPDGDD:

Toda persona tiene derecho a solicitar motivadamente de los medios de comunicación digitales la inclusión de un aviso de actualización suficientemente visible junto a las noticias que le conciernan cuando la información contenida en la noticia original no refleje su situación actual como consecuencia de circunstancias que hubieran tenido lugar después de la publicación, causándole un perjuicio.

En particular, procederá la inclusión de dicho aviso cuando las informaciones originales se refieran a actuaciones policiales o judiciales que se hayan visto afectadas en

97 En cuanto a ello, el considerando 153 señala que las excepciones que a los derechos deben establecer los Estados miembros cuando el tratamiento de datos se haga con fines periodísticos para conciliar la protección de datos con la libertad de información deben aplicarse «en particular al tratamiento de datos personales en el ámbito audiovisual y en los archivos de noticias y hemerotecas».

Otra manifestación del derecho al olvido se prevé en el art. 94 en relación con las redes sociales. 
beneficio del interesado como consecuencia de decisiones judiciales posteriores. En este caso, el aviso hará referencia a la decisión posterior.

Se trata, por tanto, del supuesto referido a una noticia veraz que informa sobre la detención o acusación de una persona por un delito determinado y que, posteriormente, es absuelta, lo que resulta acorde con lo señalado por el TEDH en los casos Wegrzynowski y Smolczewski c. Polonia y Times Newpapers Ltd (n. ${ }^{\circ} 1$ y 2) c. Reino Unido. En este caso, y a nuestro juicio, la actualización debe llevarse a cabo cuando el sujeto involucrado en la noticia tiene relevancia pública, mientras que, si no la tiene, la medida adecuada para la protección de sus datos personales es la supresión de los mismos o su sustitución por iniciales. Cierto es que este precepto no hace referencia alguna al derecho al olvido. Sin embargo, la expresión de que «la información contenida en la noticia original no refleje su situación actual» permite apreciar una cierta relación entre este derecho y el del olvido.

En cuanto al art. 93.1 LOPDGDD, recoge un auténtico derecho a la desindexación al reconocer a toda persona la facultad de exigir que:

[...] los motores de búsqueda en Internet eliminen de las listas de resultados que se obtuvieran tras una búsqueda efectuada a partir de su nombre los enlaces publicados que contuvieran información relativa a esa persona cuando fuesen inadecuados, inexactos, no pertinentes, no actualizados o excesivos o hubieren devenido como tales por el transcurso del tiempo, teniendo en cuenta los fines para los que se recogieron o trataron, el tiempo transcurrido y la naturaleza e interés público de la información.

Así, y tal y como hicieron el TS y el TC, se reconoce un derecho al olvido sobre la base del principio de la calidad de los datos y se establece expresamente en el apdo. 2 del mismo precepto que el ejercicio del derecho en cuestión no impedirá en ningún caso el acceso a la información completa tal y como fue publicada en la página web, si bien no se podrá encontrar a partir del nombre de quien ejerciera el derecho, protegiéndose de este modo la integridad de las hemerotecas. Además, el hecho de que el artículo en cuestión se refiera a los «motores de búsqueda en Internet», sin diferenciar entre los generales o externos y los internos, permite afirmar que el legislador ha optado por ofrecer la misma respuesta al conflicto en cuestión que la que aportó el TC en la sentencia que ha sido analizada en este trabajo.

Pues bien, aunque nos parece mucho más acertada la solución legal aportada a estos supuestos por la legislación española que la europea, nos surgen serias dudas acerca de su legalidad, teniendo en cuenta que el RGPD es una norma jerárquicamente superior a la LOPDGDD y que el alcance dado por 
el Reglamento al derecho de supresión es mucho más amplio que el que le confiere la ley española. Veremos quién gana.

\section{Bibliografía}

Aberasturi Gorriño, U. (2016). Derecho a ser olvidado en Internet y medios de comunicación digitales. A propósito de la Sentencia del Tribunal Supremo de 15 de octubre de 2015. Revista Española de Derecho Administrativo, 175, 259-290.

Aparicio Salom, J. (2018). Derechos del interesado. En J. López Calvo (coord.). El nuevo marco regulatorio derivado del Reglamento Europeo de Protección de Datos (pp. 363-400). Madrid: Wolters Kluwer.

Arias Máiz, V. (2010). Una excepción al principio del consentimiento informado no contemplado en el artículo 6 LOPD: el uso de datos personales por medios de comunicación. En A. Troncoso Reigada (dir.). Comentario a la Ley Orgánica de protección de datos (pp. 295-321). Cizur Menor: Aranzadi.

Arenas Ramiro, M. (2013). Hacia un futuro derecho al olvido de ámbito europeo. En J. Valero Torrijos (coord.). La Protección de los Datos Personales en Internet. Riesgos, amenazas y respuestas desde la perspectiva jurídica (pp. 325-380). Cizur Menor: Aranzadi.

Article 29 Data Protection Working Party. Guidelines on the Implementation of the Court of Justice of the European Union Judgment on "Google Spain and Inc v. Agencia Española de Protección de Datos (AEPD) and Mario Costeja González" C-131/12, de 26 de noviembre de 2014. Disponible en: https://bit. ly/2D6eSqW.

Berrocal Lanzarot, A. I. (2017). Derecho de supresión de datos o derecho al olvido. Madrid: Reus.

Brotons Molina, O. (2013). Caso Google: tratamiento de datos y derecho al olvido. Análisis de las Conclusiones del Abogado General, Asunto C-131/12. Revista Aranzadi de Derecho y Nuevas Tecnologias, 33, 107-126.

Comité de Ministros del Consejo de Europa (2012). Recommendation CM/Rec(2012)3 of the Committee of Ministers to member States on the protection of human rights with regard to search engines, de 4 de abril de 2012. Disponible en: https://tinyurl.com/yyfsjhhg.

Cotino Hueso, L. (2010). Datos personales y libertades informativas. Medios de comunicación social como fuentes accesibles al público. En A. Troncoso Reigada (dir.). Comentario a la Ley Orgánica de protección de datos (pp. 295-321). Cizur Menor: Aranzadi.

De Verda y Beamonte, J. R. (2015). Los derechos al honor, a la intimidad y a la propia imagen como límites del ejercicio de los derechos fundamentales de información y expresión: ¿ Una nueva sensibilidad de los tribunales? Derecho Privado y Constitución, 29, 389-436. Disponible en: http://dx.doi.org/10.18042/cepc/ dpc.29.10. 
De Vries, K. (2018). Right to Respect for Private and Family Life. En P. van Dikj, F. van Hoof, A. van Rijn y L. Zwaak, L. (eds). Theory and Practice of the European Convention on Human Rights (pp. 667-733). Cambridge: Intersentia.

Di Pizzo Chiacchio, A. (2018). La expansión del derecho al olvido digital. Efectos de "Google Spain» y el Big Data e implicaciones del nuevo Reglamento Europeo de Protección de Datos. Barcelona: Atelier.

Jiménez-Castellanos Ballesteros, I. (2018). El derecho al olvido digital del pasado penal [tesis doctoral]. Universidad de Sevilla. Disponible en: https://hdl.handle. net/11441/75092.

Korenhof, P., Ausloos, J., Szekely, I., Ambrose, M., Sartor, G. y Leenes, R. (2015). Timing the Right to Be Forgotten: A Study into "Time" as a Factor in Deciding About Retention or Erasure of Data. En S. Gutwirth, R. Leenes, y P. de Hert (eds.). Reforming European Data Protection Law (pp. 171-201). Dordrecht: Springer. Disponible en: https://doi.org/10.1007/978-94-017-9385-8_7.

Lazkano Brotóns, I. (2015). Artículo 10. Libertad de expresión. En I. Lasagabaster Herrarte (dir.). Convenio Europeo de Derechos Humanos. Comentario sistemático (pp. 510-630). Cizur Menor: Aranzadi.

López Calvo, J. (2018). Últimas resoluciones judiciales sobre el «derecho al olvido». Sobre la inalterabilidad de las hemerotecas digitales. Diario La Ley, 20.

Mantelero, A. (2012). Right to be forgotten ed archivi storici dei giornali. La Cassazione travisa il diritto all'oblio. La nuova Giurisprudenza Civile Commentata, 10, 843-849.

Mieres Mieres, L. J. (2014). El derecho al olvido digital. Fundación Alternativas. Documento de trabajo 186/2014. Disponible en: https://tinyurl.com/y6fuqr27.

Pazos Castro, R. (2016). El derecho al olvido frente a los editores de hemerotecas digitales. A propósito de la STS (Pleno de la Sala 1a) de 15 de octubre de 2015. InDret. Revista para el análisis del Derecho, 4, 1-49. Disponible en: http://www. indret.com/pdf/1265_es.pdf.

Pizarro Moreno, E. (2016). Celada al derecho al olvido. Comentario a la Sentencia del Tribunal Supremo de 15 de octubre de 2015 (RJ 2015, 545). Revista Aranzadi de Derecho y Nuevas Tecnologias, 41, 327-342.

Rallo, A. (2014). El derecho al olvido en Internet. Google versus España. Madrid: Centro de Estudios Políticos y Constitucionales.

Seligrat González, V. M. (2015). El «derecho al olvido digital». Problemas de configuración jurídica y derivados de su incumplimiento a la vista de la STS de 15 de octubre de 2015. Actualidad Civil, 12, 62-71.

Simón Castellano, P. (2015). El reconocimiento del derecho al olvido digital en Españay en la UE. Efectos tras la sentencia del TJUE de mayo de 2014. Barcelona: Bosch. 